\title{
Review Article \\ Natural Products for the Management and Prevention of Breast Cancer
}

\author{
Sarmistha Mitra $\mathbb{D}^{1}$ and Raju Dash $\mathbb{D}^{2}$ \\ ${ }^{1}$ Department of Pharmacy, University of Chittagong, Chittagong 4331, Bangladesh \\ ${ }^{2}$ Department of Biochemistry and Biotechnology, University of Science and Technology Chittagong, Chittagong 4202, Bangladesh
}

Correspondence should be addressed to Raju Dash; rajudash.bgctub@gmail.com

Received 5 September 2017; Revised 18 December 2017; Accepted 16 January 2018; Published 26 February 2018

Academic Editor: Kuzhuvelil B. Harikumar

Copyright (C) 2018 Sarmistha Mitra and Raju Dash. This is an open access article distributed under the Creative Commons Attribution License, which permits unrestricted use, distribution, and reproduction in any medium, provided the original work is properly cited.

\begin{abstract}
Among all types of cancer, breast cancer is one of the most challenging diseases, which is responsible for a large number of cancer related deaths. Hormonal therapy, surgery, chemotherapy, and radiotherapy have been used as treatment of breast cancer, for a very long time. Due to severe side effects and multidrug resistance, these treatment approaches become increasingly ineffective. However, adoption of complementary treatment approach can be a big solution for this situation, as it is evident that compounds derived from natural source have a great deal of anticancer activity. Natural compounds can fight against aggressiveness of breast cancer, inhibit cancerous cell proliferation, and modulate cancer related pathways. A large number of research works are now focusing on the natural and dietary compounds and trying to find out new and more effective treatment strategies for the breast cancer patients. In this review, we discussed some significant natural chemical compounds with their mechanisms of actions, which can be very effective against the breast cancer and can be more potent by their proper modifications and further clinical research. Future research focusing on the natural anti-breast-cancer agents can open a new horizon in breast cancer treatment, which will play a great role in enhancing the survival rate of breast cancer patients.
\end{abstract}

\section{Introduction}

Breast cancer is an important public health problem worldwide [1], which is the second most common cancer diagnosed and is also a prime reason of death in women globally [2]. It has become a fatal disease, and risk factors associated with breast cancer seem to be expanding day by day [3]. A number of exogenous and endogenous factors can stimulate the pathology of breast cancer and can worsen the situation [4]. Some additional factors like side effects of conventional treatment such as chemotherapy [5] and radiotherapy [6] are increasing the burden more and making it more challenging to treat the patients of breast cancer. One of the most threatening problems with conventional treatment is multidrug resistance (MDR) [7, 8]. Due to this reason, the survival rate of breast cancer patient is very unsatisfactory. In order to face this deadly situation, many research works are now designed dedicatedly to find out the alternative treatment system of breast cancer which can be used as therapeutics, as an adjuvant treatment besides other treatments, or as chemopreventive agents [9-12]. The etiology of breast cancer and proliferation of cancerous cells is generally mediated by a number of mechanisms or pathways [13-16]. Again there are a number of biomarkers used for diagnostic process [17]. Any of these mechanisms can be targeted by a compound derived from natural source and can be established as a treatment approach [18]. Till now, more than 50\% of drugs have been designed from natural compounds and, among them, $75 \%$ of anticancer drugs were designed and developed from the plant derived natural ingredients [19].

Natural products derived from a variety of sources may have the tendency to stimulate many physiological pathways which can be beneficial for ailment of stubborn diseases [20] like cancer [21]. For many years cancer remains a very complex disease to treat effectively; the application of different strategies to treat cancer becomes mandatory. To solve this complex puzzle, plant derived compounds are explored. A great number of researches have been carried 


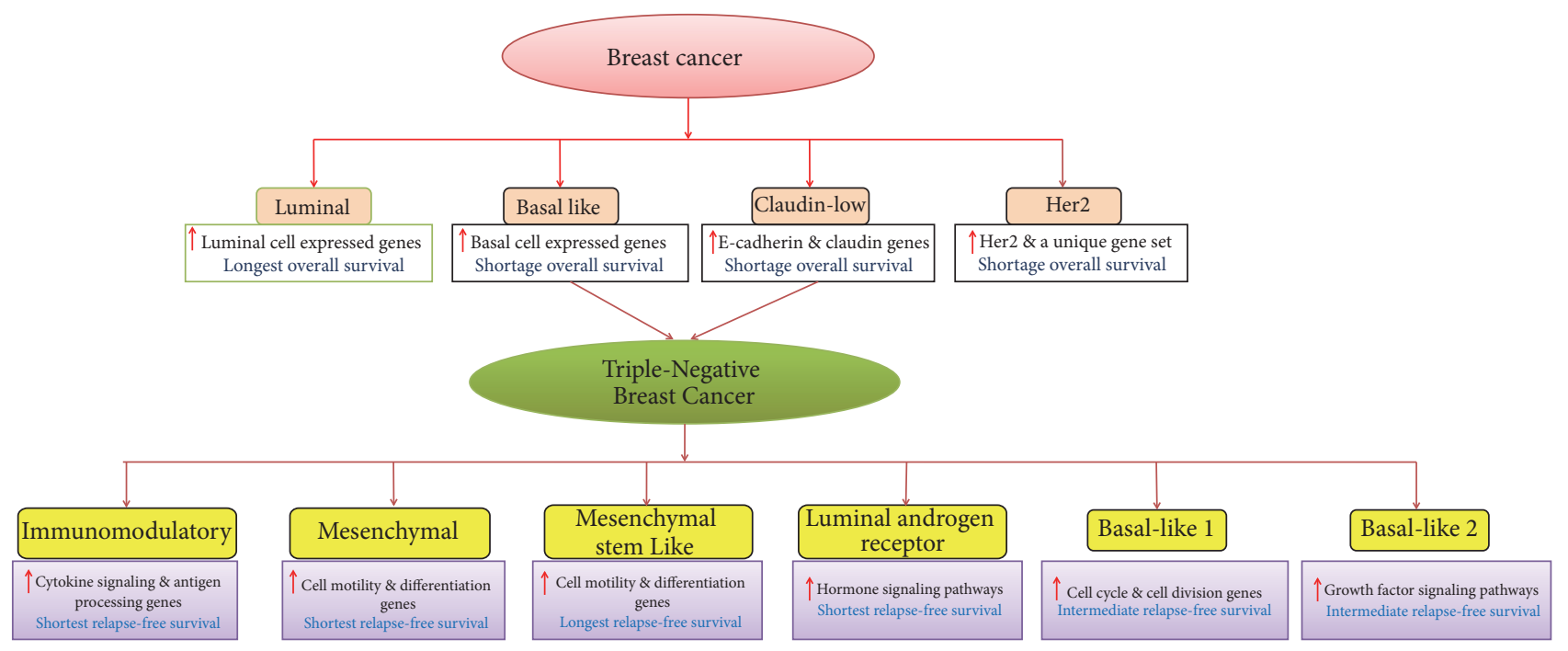

FIGURE 1: Schematic representation of molecular subtypes of breast cancer (Perou et al. [26-28] denoted by pink color) and triple-negative breast cancer types (Lehmann et al. [29] denoted by yellow colour). Red arrow mark indicates the higher expression of cellular gene in each subtype. The subtypes are characterized by overall survival (for breast cancer subtypes) and relapse-free survival (for TNBC subtypes).

out to design cancer therapeutics from natural compounds especially from phytochemicals [22, 23]. Recent studies suggested that natural compounds from dietary sources can target a number of pathways related to breast cancer, which can give a positive feedback against malignancies and can also play a key role in preventing breast cancer [24]. In this review, some critical and significant mechanisms related to breast cancer are highlighted, and, on the basis of the key components of the mechanisms, some phytochemicals are discussed and their mechanisms and potentiality to fight with breast cancer are featured. The mechanisms of breast cancer development like epigenetic modifications, aromatase activity, arachidonic acid pathway and cell apoptosis pathway, and natural compounds acting against these mechanisms are discussed. These phytochemicals can mitigate the harmful adverse effects of conventional treatment [25] and also help a patient to fight with mental distress and anxiety. From many studies, it has been established that natural compounds from plants as well as from dietary sources can be very helpful to treat breast cancer, and also many compounds are suggested to work with great efficacy. Therefore, this work is trying to accumulate the most effective natural compounds which can control one or more than one of these pathways and become a successful potential treatment approach.

\section{Different Subtypes of Breast Cancer}

Basically, ductal hyperproliferation is the initial stage of breast tumor development, where different carcinogenic factors play major roles to turn this stage into benign tumors or even metastatic carcinomas [30]. According to the genome profiling of breast tumors, several molecular forms of breast cancer were first classified by Perou et al. $[26,27]$ concluding the four primary subgroups of breast tumor (shown in Figure 1). Gene overexpression and overall survival are the two main factors to characterize these subtypes, as overexpressions of genes are normally associated with luminal and basal-like subtypes and also correlated with the longest and shortest survival, respectively, while HER2 subtype is associated with the overexpression of EGFR and unique set of genes is also correlated with the short survival. It should be noted that the responsible drivers for the poor survival of basal-like tumors still remain unclear. Later, Prat et al. [28] reported another subtype claudin low tumor that is associated with high expression of epithelial-tomesenchymal transition markers, immune response genes, and cancer stem cell-like features. However, this subtype shows low to absent expression of luminal differentiation markers, which is correlated with decreased survival [31]. Interestingly, both of these subtypes have the high molecular heterogeneity and significantly cover the common characteristics of triple-negative breast cancers (TNBCs). The TNBCs are highly aggressive in nature and generally characterized as the lacking expressions of three biomarkers, that is, ER, $\mathrm{PR}$, and HER2 proteins. The development of targeted therapy in TNBC is very challenging, though Lehmann et al. [29] reported six different TNBC subtypes. Each subtype of breast tumor would respond differently to treatment, which made breast cancer extremely intractable [32]. As described in Figure 1, each TNBC subtype represents different gene expressions and survivals, which make it more challenging to define accurate selection of chemotherapeutics or drugs that are both effective and safe to breast cancer patient.

\section{Conventional Treatment and Its Drawbacks}

Presently applicable treatment strategies for patients of breast cancer include surgery, radiotherapy with an adjuvant chemotherapy, and hormone therapy which can provide positive feedback [33]. Two early stages of breast cancer, stages I and II, are usually treated with breast-conserving surgery and radiation therapy. Radiation therapy following 
breast-conserving surgery reduces the risk of death and recurrence [34]. However, it has been reported that there can be an incidence of brachial plexopathy, rib fracture, tissue necrosis, pericarditis, and second non-breast infield malignancies occurring in patients with early stage breast cancer treated with surgery and radiation therapy [35]. In case of TNBC treatment, the only successful and systemic therapy is "chemotherapy."

Multidrug resistant (MDR) tumors are another threat towards cancer therapy and are a very serious cause of cancer related deaths in patient. Therefore, understanding the molecular basis of MDR and developing medicines as well as treatment regimens to prevent drug resistance is an important priority [36]. A number of complex mechanisms can be directly related to the occurrence of drug resistance, including modification of drug efflux membrane transporters, namely, P-glycoprotein, MRP 1, BCRP [37, 38], and alterations in beta-tubulin [38]; multidrug resistance protein (MRP) family consists of 9 members (MRP1-9) [39]. Many drugs which were previously very successful such as anthracyclines (doxorubicin, daunorubicin, epirubicin, and mitoxantrone), taxanes (paclitaxel, docetaxel), and capecitabine can be resistant to a patient [40], and it is suggested by Fumoleau et al. to administer monotherapy in breast cancer treatment. Again there is a fact that cancer stem cells are immune to any therapies and they have the ability to maintain "stemness." It is their unique ability to continue to populate tumor mass again and again with an increasing supply of new cancer cells [41].

Furthermore, major side effects of chemotherapy may lead to the reduction of white blood cells and red blood cells thus increasing the possibility of infection and anemia, respectively, with reduced oxygen carrying capacity of the cells. Another significant side effect is hair loss resulting from conventional treatment. Fatigue, sore throat, nausea, ulcers, loss of appetite, change in taste, constipation, diarrhea, change in skin color, and various hormonal changes are other side effects which are also observed during these treatments [42].

On the basis of all these understandings, finding out an alternative approach of breast cancer management is an urgent need that can avoid and minimize the risks of unusual side effects of conventional treatment approaches.

\section{Herbal Approach in Treatment of Breast Cancer}

Natural compounds or phytochemicals provide positive health benefits by acting directly on specific molecular targets such as genes, or by indirectly stabilizing conjugates that affect metabolic pathways [43]. Liao et al. in 2013 reported that herbal compounds can be effectively used as adjuvants with conventional chemotherapy with a view to reducing side effects like fatigue, nausea, mucositis, and anemia arising from chemotherapy or other treatments [44]. From many studies, it is evidenced that many of the natural compounds have anticancer activity and they have the property to function as a treatment approach via many mechanisms (Figure 2) [45-48]. In the early genesis of cancer and progression, epigenetic dysregulation is mostly observed besides genetic changes. Epigenetic modification involves changing of cellular phenotype without involvement of modification of underlying DNA sequence. The mechanisms comprise the DNA methylation, mainly at cytosines (creating the 5methylcytosine) when positioned next to a guanine (CpG dinucleotides), methylation, acetylation, phosphorylation, ubiquitination, and sumoylation of histones and noncoding RNAs or miRNAs that affect the expression of mammalian genome [49]. In breast cancer, abnormal histone modifications like acetylation and methylation of histone along with DNA hypermethylation are associated with epigenetic silencing of tumor suppressor genes and genomic instability $[50,51]$. In this context, the readers are suggested to refer to some recent reviews describing the functional roles of epigenetics and the possible epigenetic targets which altered expressions and are commonly associated with the breast cancer development and progressions [52, 53]. Accumulating evidences showed that natural phytochemicals including the secondary metabolites found in the dietary foods have the ability to modulate the epigenetic events and reverse the epigenetic changes before causing cancer progression [54, 55]. By targeting specific key transcription factors, kinases, and growth factor receptor mediated pathways, phytochemicals are reported to exert their actions in epigenetic alterations through cell cycle arrest, initiating apoptosis and reactivation of tumor suppressing genes [56, 57]. In breast cancer chemoprevention, the article reported by Chlebowski [58] showed the effective chemopreventive actions of tamoxifen and some aromatase inhibitors including exemestane and anastrozole in reduction of breast cancer on clinical trial studies. However, these drugs showed favorable side effects, including tamoxifen, that increase the greater risk of endometrial cancer. Compared to the synthetic drugs, natural compounds are very much promising in breast cancer chemoprevention, as they showed less side effects and minimal toxicity in both in vitro and in vivo experiments [59]. Aromatase, a membrane bound protein and a member of the cytochrome P450 enzyme family, catalyzes the conversion of androstenedione to estrone (E1) and of testosterone to estradiol (E2) and plays a very significant role in biosynthesis of estrogen [60]. A number of recent studies showed that phytochemicals have the similar chemical structure to estrogen and have the ability to alter aromatase expression by directly inhibiting the aromatase activity [61]. Furthermore, evidences also reported that natural products also show chemopreventive actions by targeting arachidonic acid (AA) pathway, including metabolic enzymes cyclooxygenases (COXs), phospholipase A2s (PLA2s), and lipoxygenases (LOXs) [62]. Many studies reported that AA pathway plays a key role in the inflammation and also in tumorigenesis [63, 64]. A highly positive association was reported between the high level of COX-2 and poor prognosis, invasiveness, and density of breast cancer cells [65]. Ranger et al. found a positive correlation between the expression levels of COX-2 and distant metastases in breast cancer [66]. By considering this, it was experimented and later found that knocking down COX2 can eventually reduce the metastatic behavior of breast cancer cells in mice [67]. To get more insight in these two 


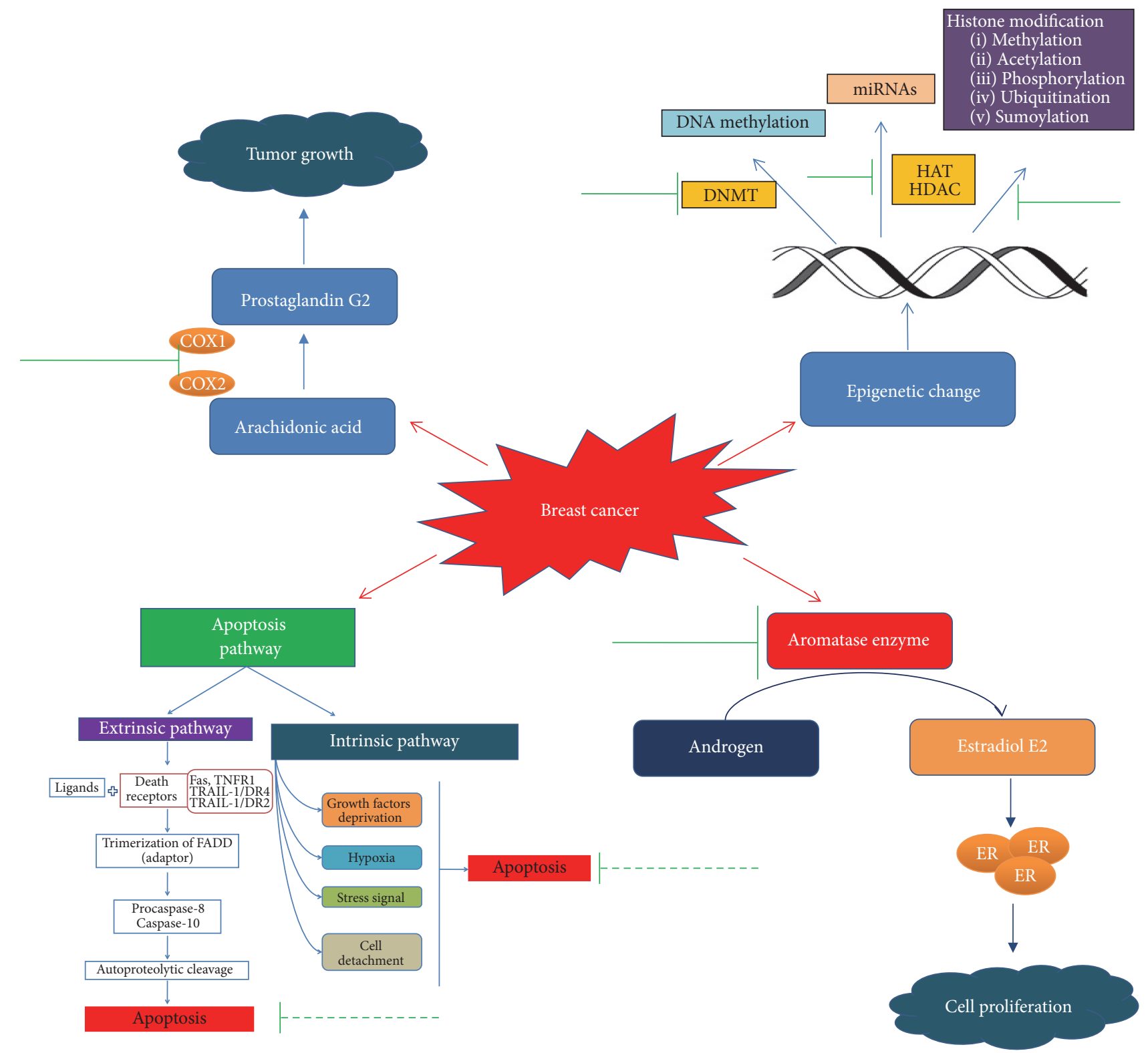

FIGURE 2: Molecular targets of natural compounds in breast cancer pathway. Here green solid line indicates the action of natural compounds as inhibitor, while green dotted line represents the upregulation induced by natural compounds.

pathways, reader is suggested to read the recent reviews on arachidonic acid metabolite by Borin et al. [68] and aromatase inhibitors by Chumsri et al. [69]. A number of phytochemicals such as curcumin, ginsetin, lycopene, and apigenin have been directly reported to inhibit biosynthesis of metabolic products such as prostaglandins and leukotrienes and, therefore, have been considered as the potent therapeutic agents in breast cancer chemoprevention.

Findings also suggested that phytochemicals have significant effects to stimulate apoptosis in malignant and premalignant cells both in vitro and in vivo [70]. Apoptosis refers to the programmed cell death that plays crucial roles for embryonic development and tissue homeostasis, and its dysregulation may cause tumor formation or even development of cancer cell drug resistance [71].
Therefore, evasion of apoptosis is considered as one of the most significant approaches to find out and design cancer treatment strategy [72]. Two main pathways related to the activation of apoptosis are extrinsic and intrinsic pathway. The extrinsic pathway starts when the ligand binds with the death receptor and ultimately triggers the trimerization and causes the recruitment of the adaptor protein Fasassociated death domain (FADD) and procaspase- 8 and/or caspase-10 to form a death-inducing signaling complexes (DISC) in the intracellular death domain [73, 74]. The death receptors are including Fas (CD95/APO-1), TNFreceptor 1 (TNF-R1/p55/CD120a), TNF-related apoptosisinducing ligand receptor 1 TRAIL-R1/death receptor 4 (DR4), and receptor 2 (TRAIL-R2/DR5/APO-2/KILLER) [75, 76]. In the DISC, caspase- 8 or caspase- 10 oligomerization activated 
DISC through autoproteolytic cleavage that leads to triggering of the enzymatic activity of downstream effector caspases, such as caspase- 3 and caspase-7 [77]. In contrast, the intrinsic mitochondrial pathway is activated by physical or chemical stimulations, such as hypoxia, growth factor deprivation, cell detachment, or stress signals, where the proapoptotic Bcl2 family members play major roles in the initiation of this pathway. [78]. Caspase-9 is also associated with the intrinsic pathway of apoptosis. Once the pathway is activated, caspase9 cleaves and activates the downstream effector caspase-3 and caspase-7, which then cleaves the key regulatory and structural proteins to execute cell death. Most extensive studies reported that many tumor promoter proteins inhibit apoptosis, by developing chemoresistance in cancer cell. Thereby targeting proteins that manipulated the apoptotic programs is considered as prominent anticancer drug targets, in which activation of apoptosis in cancer cells is the primary concern [79, 80]. Currently, many studies are focusing on the natural compounds that have been approved for the clinical use in the treatment of cancer to find out their ability to inhibit the growth of cancer cells by inducing apoptosis through one or more than one mechanism [81, 82].

\section{Natural Compounds as Therapeutics}

5.1. 3,3'-Diindolylmethane. 3,3'-Diindolylmethane (DIM) is a natural compound that is abundant in cruciferous vegetables such as broccoli, cauliflower, and cabbage and it is a major acid condensation product of indole-3-carbinol (I3C) [170]. In acidic condition, I3C is converted to DIM in the stomach [171]. Experimental evidences suggested that DIM inhibited COX-2 expression induced by aryl hydrocarbon receptor in human breast cancer cell [83]. Fan et al. [172] demonstrated that DIM stimulated the phosphorylation of Brcal during the oxidative stress and played protective roles. Further studies showed that DIM inhibits the expression of angiogenesis expressing genes including surviving [84] and hypoxia-inducible factor-1 [85]. In combination therapy with herceptin, DIM reduced the expression of FoxM1 in HER-2/Neu-expressing breast cancer cells through downregulating Akt and NF-kB p65 [87]. Similar result is also observed by Ahmad group in case of Taxotere, in which DIM also targeted FoxM1 [88]. Consequently, in a randomized, placebo-controlled trial studies, DIM significantly increased the chemosensitivity of tamoxifen and showed favorable effect on estrogen metabolism [89]. Similarly, Wang et al. showed that DIM sensitized $\gamma$-radiation and induced apoptosis through cell cycle arresting at G2/M phase and also increased intracellular ROS generation [173]. DIM also upregulates the expression of CYP19 in MDA-MB-231 cells and decreases aromatase expression in MCF-7 cells thereby acting as an aromatase inhibitor [86]. Significant tumor inhibition by DIM was also observed in rodent model [174, 175]. Despite significant efficacy of DIM on breast cancer treatment, Marques et al. [176] recently showed that DIM induced cellular proliferation at concentration of $10 \mu \mathrm{M}$ by activating estrogen receptor $\alpha$ signaling pathways, in the absence of estradiol, indicating adverse risk of taking DIM as dietary supplement. However, further research should be needed to understand the unexpected adverse effects of DIM supplement for the treatment or prevention of breast cancer.

5.2. Biochanin A. Biochanin A is an isoflavone extracted from red clover (Trifolium pratense) which is known to have anticancer activity [177]. It was reported by Wang et al. [90] that, by assaying MCF-7 cells stably transfected with CYP19 gene, biochanin A blocked the activity of aromatase enzyme and stopped cell growth attributing to the enzyme activity. Furthermore, in SK-BR3 cells (ER-negative breast cancer cells), biochanin A was found to inhibit aromatase enzyme activity and reduce mRNA expression. Genistein is a metabolite of biochanin $\mathrm{A}$, which was also found to suppress promoter I.3/II activation and function as an AI. It was reported that biochanin $\mathrm{A}$ is tolerated better than genistein and causes positive expression of tumor suppressor genes in HMEC, MCF 12A, and MCF7 (ER-positive breast cancer cell line) cell lines [91, 178]. Similar finding was also observed by Young et al., in which biochanin A showed better induction on tumor suppressor gene expression compared to genistein [179]. Bhushan et al. reported that biochanin A inhibited cell viability, signaling pathways, and invasive enzyme expression and activity in SK-BR-3 cancer cells [91]. Another study done by Moon et al. in xenograft mouse model showed that biochanin A was effective to decrease the growth of estrogen-dependent MCF-7 tumors at doses of 5 or $15 \mathrm{mg} / \mathrm{kg}$ per day [92]. Nevertheless, the effect of biochanin $A$ in the other pathways of breast cancer progression still needs to be clarified and the further studies in clinical trial settings are also required to understand the bioavailability and the therapeutic regimen of biochanin A and its metabolic profile in different breast cancer patient's types. As most of the experimental studies are conducted in ER-positive cell line, particular role of biochanin A on ER-negative or triplenegative breast cancer cells should be focused on more in future researches.

5.3. Curcumin. Curcumin, the active ingredient of turmeric, is known as a polyphenolic compound and has a very widespread medicinal activity including anti-breast-cancer activity. Curcumin can exert its activity by mediating a number of pathways. Curcumin is reported to induce breast cancer apoptosis by regulating the expression of apoptosis related genes and proteins [180]. Recent works suggest that curcumin can induce apoptosis in breast cancer cell by enhancing the level of p53 which in turn induces Bax expression, leading to an elevated $\mathrm{Bax} / \mathrm{Bcl}-2$ ratio. This cascade of events leads to programmed death of breast cancer cells [181].

It was reported that curcumin can downregulate NF- $\kappa \mathrm{B}$ expression which is a signaling molecule playing important part in cell proliferation. By reducing expression of NF- $\kappa \mathrm{B}$ curcumin can exert antiproliferation effect on MDA-MB231 and BT-483 cells [93]. Another study suggested that curcumin can decrease the protein expression of urokinasetype plasminogen activator via NF- $\kappa \mathrm{B}$ activation which can ultimately stop the adhesion and invasive nature of MCF-7 cells and can suppress metastatic progression of breast cancer [182]. A number of works studied and evaluated the impact 
of curcumin on NF- $\kappa$ B signaling which can be explored for further study $[183,184]$.

Curcumin can also show its activity on cancer stem cells which can be a potential strategy of breast cancer treatment. Kakarala et al. [94] reported that curcumin inhibited Wnt signaling in MCF7 cells which is dysregulated in breast cancer $[185,186]$; this pathway plays an important role in breast stem cell self-renewal. By inhibiting this pathway, curcumin is proved to be a very promising agent for anti-breast-cancer treatment.

Again it shows epigenetic activity which can be a treatment field. Curcumin is a potential modulator of histones and it regulates enzymatic function of HATs and HDACs. It is evident that curcumin blocks the expression of class I HDACs [95]. Additionally it upregulates the expression of some miRNAs involved in carcinogenesis to reduce the expression of Bcl-2 [96].

Curcumin can also enhance the activity of chemotherapeutic agents. Curcumin inactivates NF- $\kappa \mathrm{B}$ expression and this can enhance the efficacy of paclitaxel. This combined effect minimizes breast cancer growth in MDAMB-231 $(\mathrm{ER}-/ \mathrm{PR}-)$ cells. This combined therapy of paclitaxel and curcumin decreases size of tumor and tumor cell proliferation with increased rate of apoptosis and downregulates MMP-9 expression [97]. Curcumin also shows synergistic effect with lots of other compounds which are discussed in other review works [43]. Curcumin can also act against the difficulty of multidrug resistance [187]. Limtrakul et al. [98] found the inhibitory activity of tetrahydrocurcumin on ATP-binding cassette $(\mathrm{ABC})$ drug transporters, including P-glycoprotein (ABCB1/P-gp), multidrug resistance protein 1 (ABCC1), and mitoxantrone resistance protein (ABCG2/MXR) which proved that curcumin is a potential chemosensitizer and acts against drug resistance.

It can be suggested that curcumin is one of the most significant compound to face the challenges of breast cancer treatment. However, the problem of curcumin is its poor bioavailability, which is a great obstacle in developing a therapeutic [188]. Hence, future works should focus on designing and developing more potent analogues of curcumin to overcome the drawbacks of poor bioavailability.

5.4. Epigallocatechin Gallate. Epigallocatechin gallate (EGCG) is one of the most phenolic catechins present in green tea and is widely known for its health-related benefits [189]. It is found that EGCG has epigenetic effects in carcinoma cell line either by demethylation or suppressed methylation of promoters of tumor suppressor genes $[100,101]$. Li et al. [190] demonstrated in a recent work that EGCG in combination with class I HDAC inhibitor, trichostatin A (TSA), could synergistically reactivate ER $\alpha$ expression in ER $\alpha$ negative MDA-MB-231 breast cancer cells by modulating histone methylation and acetylation pattern at the gene promoter. It is reported by Deb et al. in 2015 [102] that treatment of breast cancer cells with EGCG could induce the expression of epigenetically repressed TIMP-3 gene. The TIMP-3 gene was mediated through modulation of epigenetic mechanisms which includes EZH2 and class I HDACs independent of the promoter DNA methylation.
After treating with EGCG, the protein levels of class I HDACs and EZH2 were reported to reduce to a great level.

Furthermore, Goodin et al. [191] suggested that EGCG inhibited the proliferation of estrogen-sensitive MCF-7 breast cancer cell line and also binds to both $\operatorname{ER} \alpha$ and $\operatorname{ER} \beta$ [192]. Induction of apoptosis by EGCG is also exerted by the ERindependent actions with the inhibition of aryl hydrocarbon(AhR-) regulated genes [103-106]. More recently, Baker and Bauer reported the antiproliferative mechanism of EGCG by blocking the ER $\beta$-specific inhibitor PHTPP [193]. In addition, EGCG is reported to induce the apoptosis in ERnegative MDA-MB-468 [104] and MDA-MB-231 cells [106, 107] and also alters the EGFR activity [108]. EGCG is also suggested to increase the protein expression of p21 and p27 [109], as well as enhanced the expression of proapoptotic genes, caspase- 3 , caspase- 8 , and caspase- 9 , and TP53 [110, 111]. Another important study demonstrated the inhibitory effects of EGCG on the arachidonic acid pathway by controlling COX-2 expression through minimizing the activity of COX-2 promoter via inhibition of nuclear factor kappaB (NFkappaB) activation [112, 113]. However, studies also showed that EGCG has no effect on the aromatase activity [194]. Moreover it is suggested that, from clinical trial based studies of breast cancer, EGCG increases the sensitivity of ionizing radiation [114] and also shows protection against the toxic adverse effects of chemotherapy and radiotherapy [195].

Furthermore, in combination therapy, the presence of EGCG significantly increased the bioavailability of tamoxifen [115], 5-fluorouracil [116], and doxorubicin [117], and also single oral doses of ECCG up to $1600 \mathrm{mg}$ were safe and very well tolerated [196]. For more detailed information regarding the effect of EGCG as adjuvant in cancer therapy, the readers are suggested to refer to Stearns et al. [117]. However, still various reports showed the undesirable interactions of EGCG with some anticancer drugs and therefore much clinical based research need to establish the effective role of EGCG as an adjuvant in breast cancer therapy.

5.5. Genistein. Soy isoflavones have been identified and proved as dietary components having a very potential and significant role in decreasing the incidence of various cancers [197]. Genistein, the predominant isoflavone content in soy products, has been known as cancer chemopreventive agent for various cancers $[118,198]$. Genistein and other soy isoflavones have been found to be successful in controlling COX-2 expression and also to antagonizing AA for controlling PGE2 [118]. Genistein prevented inflammatory responses by inhibiting sPLA2 activity [119]. Soy isoflavones, especially genistein, minimizes COX-2 expression in MCF-7 breast cancer cells, which could be the mechanism underlying prevention of breast carcinogenesis [120]. Chung et al. [121] demonstrated that genistein inhibited TPA-induced COX-2 expression and transcriptional activity of NF- $\kappa \mathrm{B}$ in MCF10A human breast epithelial cells by blocking ERK mediated phosphorylation of p65. This study supported the chemopreventive effect of genistein against breast cancer. Due to having structural resemblance with the estradiol (E2), genistein binds and activates both $\operatorname{ER} \alpha$ and $\operatorname{ER} \beta$ [122]. As a result, it is assumed that the estrogenic effect of soy isoflavones like 
genistein may potentially increase the risk of breast cancer in Western countries [199] and reduce the risk of breast cancer prevalence in Asian countries, as they consume high soy foods [200]. Similar studies done by Zhang and colleagues reported the lower breast cancer rate in North American women; those are consume soy products [201]. These studies thence concluded that genistein acts as ER modulator [202] like tamoxifen and raloxifene, which are the most used drugs in breast cancer treatment and prevention. It is also reported that genistein induced apoptosis via the upregulation of Bax and p21WAF1 proteins in MDA-MB-231 cell lines [123] and also downregulated the expression of caspase-3 [124].

Some other studies also provided the information about genistein inducing apoptosis. Shim et al. reported that genistein was capable of inducing apoptosis in MCF-7 cells by controlling calpain-caspase-7 and protein kinase activation cascade and apoptosis signaling kinase 1-p38 mitogenactivated protein kinase activation cascades, which involved a mechanism of release of $\mathrm{Ca}$ from the endoplasmic reticulum [125]. Sergeev also suggested that genistein targets Ca2+dependent proteases in breast cancer cells, and the apoptotic mechanism followed by genistein is based on the cellular $\mathrm{Ca} 2+$ regulatory activity [203].

Genistein can also exert its anti-breast-cancer activity by inhibiting cell proliferation. Chen et al. reported that by inactivating the IGF-1R-PI3K/Akt pathway and reducing the $\mathrm{Bcl}-2 / \mathrm{Bax}$ mRNA and protein expressions genistein can block the cell proliferation [126].

Another study suggested that genistein can enhance G2/M arrest by activating the ATM/Chk2/Cdc25C/Cdc2 checkpoint pathway and eventually increases the radiosensitivity of both [127] ER+ and ER- breast cancer cells by an apoptosis pathway mediated by mitochondria.

Genistein can be effective to control early breast tumorigenesis by epigenetic regulation. It can regulate $p 21$ and $p 16$ by playing a role in histone modifications [128]. Studies also suggested that it can epigenetically restore $E R \alpha$ expression, which ultimately induces sensitivity of TAM-dependent antiestrogen therapeutic [204]. Another study reported that the anticancer effect of genistein on breast carcinoma can be because of its ability of demethylation and reactivation of methylation-silenced TSGs by interacting with the DNMT1 catalytic domain and blocking the expression of DNMT1 [129].

Vissac-Sabatier et al. 2003 [205] found that genistein can uprise the regulation of Brcal and Brca 2 mRNA expressions in adult ovariectomised rats. However, the outcome in mice inoculated with mammary tumour cells from conditional Brcal-/- mice showed that genistein is able to reduce the size of the tumours by $50 \%$. This indicates that genistein can be protective in the absence of functional Brcal [130].

Several studies reported that genistein processes low oral bioavailability [206, 207], despite much attempts recently made to increase the oral bioavailability [208-210]; more clinical based research will be required before recommending the intake of genistein in breast cancer therapy.

5.6. Lycopene. Lycopene is the bright red carotene pigment belonging to tetra terpenoids and a phytochemical, which occurs naturally in tomato, carrot, watermelon, papaya, and cherry. Being a potent antioxidant it regulates multiple genes which are involved in DNA repair mechanism, control of cell cycle, and apoptosis in breast cancer cells [211, 212]. Studies by King-Batoon et al. [131] demonstrated the activity of lycopene on GSTP1 gene in breast cancer cells. It was observed that lycopene $(2 \mu \mathrm{M}$ for 1 week) upregulated the expression of GSTP1 and has the ability to demethylate GSTP1 promoter in MDA-MB-468 cell line; however, the scenario is not similar in MCF-7 breast cancer cells. The expressions of other genes such as RAR $\beta 2$ and HIN1 remained unaltered by lycopene treatment in MCF-7 and MDA-MB-468 breast cancer cells [131, 213]. In addition, lycopene can induce cell apoptosis and exert antitumor effects by regulating cell growth factor signaling pathways and thereby activate cell cycle arrest. Similar study done by Takeshima et al. [132] showed that lycopene potentially inhibited cell proliferation by blocking the phosphorylation of Akt following its downstream pathway and also upregulated the proapoptotic Bax without affecting antiapoptotic Bcl-xL in triple-negative breast cancer cells. Lycopene was also found to suppress cyclin D1 with the upregulation of p21 and also sustained the activation of the ERK1/2. After that, Peng et al. uncovered the antiproliferative mechanism of lycopene in MCF-7 cell lines, in which lycopene regulated the expression of p53 and Bax and thereby reduced the cell proliferation and increased apoptosis [133]. The mechanisms of lycopene in case of ER subtypes still remain controversial, where one group reported the negative correlation of lycopene and other carotenoids with ER (-) subtypes [214], while other groups demonstrated that consumption of carotenoids like lycopene could diminish the risk of the ER (-) subtypes [215]. Therefore, more studies are still necessary to elucidate chemopreventive mechanism of lycopene in other pathways as well as in different breast cancer subtypes. Besides, Rao and Shen [216] recommended a dose of lycopene with a range of 5 to $10 \mathrm{mg} /$ day, which is effective to protect cell damaging from free radicals. Though in a clinical based study it is reported that supplementation nutritional extract containing lycopene reduced the oxidative stress and carcinogenesis in prostate cancer patients [217], still there is limited study of health benefits of lycopene alone, and further clinical trial based studies on the chemopreventive effect of lycopene are to be investigated.

5.7. Shikonin. Shikonin, mainly isolated from the root extract of Lithospermum erythrorhizon, has been reported to have anticancer, anti-inflammatory, wound healing, antiviral, and a wide range of biological effects [218]. In breast cancer pathway, shikonin was found to inhibit estrogen stimulated cell growth and initiates ER ubiquitination which in turn activates ER degradation in ER-positive breast cells [143]. Reports from the experiment conducted by Yao group demonstrated that shikonin inhibited pS2 and c-myc and estrogen responsive gene promoters in breast cancer cell and also make protection against estrogen induced DNA damage by triggering the Nrf2 pathway [144]. In ERpositive breast cancer cell, shikonin induces apoptosis with the characteristics of necroptosis [219] and also decreases 
the expressions of steroid sulfatase genes [145]. Multiple pathways like activation of caspase-3, suppression of the NF- $\kappa$ B pathway, and apoptosis-related genes Bcl-2 and Bax modification are targeted by shikonin during the induction of apoptosis. Shikonin also suppresses NF- $\kappa$ B pathway through the downregulation of $\mathrm{p} 65$ and inhibition of $\mathrm{I} \kappa \mathrm{B}-$ $\alpha$ phosphorylation [146]. Jang et al. reported that shikonin blocked migration and invasion mechanism in breast cancer cell through modulating matrix metalloproteinase-9 (MMP9) [220], while Wang et al. reported that shikonin suppress ER-negative human breast cancer cell growth by inhibiting the expression of HIF-1a [221]. Furthermore, shikonin also increases the chemosensitivity of taxol in ER-negative human breast cells, inducing the cell cycle arrest at the G2/M phase, and also inhibits the activation of ERK, Akt, and p70S6 kinases, which are the major player of cancer drug resistance [147].

Zhang et al. showed that shikonin decreases tamoxifen resistance by inducing uc.57 in MCF-7R breast cancer cells that inhibits PI3K/Akt and MAPK signaling pathways through downregulating BCL11A [148]. In vivo pharmacokinetics studies represented shikonin as lower toxic [222], and this compound has potential to be considered further for the drug studies against breast cancer. However, shikonin results in poor bioavailability profiles and undergoes extensive firstpass metabolism [223]; therefore, extended studies are necessary to enhance the bioavailability profile of shikonin. And also, clinical application of shikonin requires more preclinical data, and clinical trials based study should be introduced to understand the efficacy of shikonin in single and adjuvant therapy in breast cancer.

5.8. Sulforaphane. Sulforaphane (SFN) is an isothiocyanate which is isolated from broccoli, water crass, broccoli sprouts, cabbage, and kale [224] and was found to inhibit proliferation, angiogenesis, and metastasis. At the same time it can induce cell cycle arrest and apoptosis in breast cancer cells. Studies by Bishayee [154] demonstrated that, in MCF7 and MDA-MB-231 breast cancer cells, SFN treatment can result in the inhibition of hTERT (human telomerase reverse transcriptase) in both dose-dependent and time-dependent manner through an epigenetic pathway which include DNA methylation and histone modifications. Studies showed that SFN exerts chemopreventive action by inducing cell cycle arrest at $\mathrm{G} 2 / \mathrm{M}$ phase through increasing the expression cyclin B1 and activates the poly(ADP-ribose) polymerase 1 and caspase family proteins followed by apoptosis in human breast cancer cell lines $[134,135]$. SFN was also demonstrated to inhibit tubulin polymerization in breast cancer cells [136]. Recently, kim et al. suggested that treatment of SFN in breast cancer cell lines resulted in the downregulation of the nuclear factor kappa B signaling pathway. SFN also decreased the expressions of Bcl-2 and phosphorylated Akt serine/threonine kinase. This study also suggested that, in a combination therapy, SFN increases chemosensitivity of paclitaxel in breast cancer cells $[137,138]$. SFN also causes the epigenetic modification by altering gene expressions of $h T E R T$ and estrogen receptor- $\alpha(E R \alpha)[139,190,225]$. Supporting this, Li et al. [139] demonstrated that SFN enhanced the sensitivity of tamoxifen by epigenetic reactivation of $E R \alpha$ in $\mathrm{ER} \alpha$-negative breast cancer, where the study was done both in vitro and in vivo. Another study demonstrated that SFN inhibits the expression of nuclear factor kappa B and COX-2 through blocking of signaling pathways mediated by ERK1/2IKK- $\alpha$ and NAK-IKK- $\beta$ [140]. It appeared from the study by Li et al. [142] that treatment of SFN in human breast cancer cell lines decreased the number and size of mammospheres as well as ALDH+ cell population, while, in NOD/SCID xenograft model, daily treatment of sulforaphane at dose of $50 \mathrm{mg} / \mathrm{kg}$ for 2 weeks decreased ALDH+ and downregulated the Wnt $/ \beta$-catenin self-renewal pathways. Another study by Li group showed that SFN decreased the expressions of SOX9 and ALDH1 in a model of ER $\alpha$-negative/basal-like DCIS and thereby eliminated tumor in vivo [141]. This group also observed that SFN caused the significant changes of DCIS stem-like cells in exosomal secretion which more closely resembles that of non-stem cancer cells [226]. These studies indicate that SFN could reprogram and eliminate CSCs [227]. In trail based studies, SFN was proved to produce chemopreventive effect in human breast tissue in a dosedependent manner [178]. Furthermore, at low dietary dose, SFN shows high absolute bioavailability; however, increasing dose reduced the bioavailability [228], while SFN is well tolerated and causes no significant toxicity in humans and can reach effective concentrations in human plasma and tissue. Therefore, sulforaphane could be a very promising adjunct to chemotherapeutic drugs, especially given the fact that most of these drugs do not have the capability to eliminate CSCs and are often followed by tumor resistance and recurrence [229]. However, additional studies including larger populationbased studies are needed to ensure the treatment and effect of SFN on chemopreventive modulation.

5.9. Resveratrol. Resveratrol (trans- $3,4^{\prime}, 5$-trihydroxystilbene), a plant derived polyphenolic compound, is present in grapes, which has been identified as potent antiaging, antiinflammatory, and chemopreventive agent that affects various molecular targets [230, 231]. Qin et al. reported that resveratrol acts as DNMT 3b inhibitor and decreases in RASSF-1 $\alpha$ methylation with increasing circulating resveratrol and it also suppresses expression of the androgen receptor [155]. By considering cellular targets related to epigenetic pathways, SIRT1 and acetyl transferase p300 were reported to be activated by resveratrol $[154,156]$. In case of triplenegative breast cancer cells, combination of resveratrol and pterostilbene applied in a dose very close to physiologically relevant dose showed synergistic $(\mathrm{CI}<1)$ growth inhibition by downregulating SIRT1. Further study done by Stefanska et al. [157] showed that resveratrol decreased the expressions of DNMT1, DNMT3a, and DNMT3b, HDACl, and methyl CpG binding protein 2 (MeCP2) in MCF-7 cell line. Several studies also represented that resveratrol binds with some important molecular targets of breast cancer pathway, including estrogen receptor- $\beta(\mathrm{ER} \beta)$, cyclooxygenase- $2(\mathrm{COX}-2)$, quinine reductase 2 (NQO2), inhibitor of kappa B kinase (IKK), and glutathione sulfotransferase (GSTP1), where COX-2 is involved in carcinogenesis/inflammation; ER $\beta$ and IKK are involved in gene modulations and transcriptional regulation; 
NQO2 and GSTP1 are phase II detoxification enzymes [158]. It is thought that resveratrol exerts chemopreventive action by altering their stability, activity, and signal transduction [159]. Resveratrol also acts as a phytoestrogen and is observed to decrease the E2-stimulated cell growth and transcription process of PR [232], while Park et al. [233] observed that this antagonistic effect is only for $\mathrm{ER} \alpha$ subtypes. A study reported by Bhat et al. showed that [234], in the presence of E2, resveratrol acts as antiestrogen and an agonist or antagonist in the absence of E2 in different breast cancer cell lines. On this side, a report from recent pilot clinical study, it has been observed that consumption of $1 \mathrm{~g}$ resveratrol per day had complimentary effects on estrogen metabolism as well as sex steroid hormone binding globulin in postmenopausal women having high body mass index [161]. In a dose-dependent manner, resveratrol was found to reduce aromatase mRNA and protein expression in SK-BR-3 cells and also suppressed the transactivation of CYP19 promoters I.3 and II [160]. Resveratrol also plays major roles in cellular apoptosis. Similarly, in MDA-MB 468 (basal subtype), resveratrol stimulates apoptosis through wild type p53-dependent pathway [162], while it promotes cell cycle arrest at S-phase and thereby induced apoptosis at a low dose in MCF-7 cells [163].

Pozo-Guisado et al. observed that resveratrol induced apoptosis by suppressing ER $\alpha$ - dependent PI3K pathway in MCF-7 cells [235], while in other cell lines, including MDAMB-231, MDA-MB-453 (basal subtype), and MDA-MB-468, induction of apoptosis was caused by inhibiting Src tyrosine kinase and signal transducer and activator of transcription 3 (STAT-3) phosphorylation pathways [236]. Reduction of Akt phosphorylation and activation of procaspase- 9 was also observed in MCF-7 cells caused by resveratrol to induce apoptosis [164].

By upregulating $\mathrm{Ca}+2$ leakage and calpain activity in MCF-7 cells, resveratrol caused programmed cell death in such a mechanism that is not controlled by caspase, whereas, in MDA-MB-231 cells, resveratrol can ultimately increase mitochondrial membrane potential to breakdown and release of cytochrome $c$ (cyt. c). Ultimately, mitochondria-derived activator of caspases or direct inhibitor of apoptosis (IAP) binding protein is activated with mitochondrial protein (Smac/DIABLO), caspase-9, and caspase-3 and thereby apoptosis is induced [165]. The cytotoxicity of tumor necrosis factor- (TNF-) related apoptosis-inducing ligand (TRAIL) can be induced by resveratrol and can also be used as an adjuvant for TRAIL-based therapies in order to minimize TRAIL that is required for suppressing growth of tumor. It also has the potential to sensitize resistant tumors to TRAIL induced apoptosis [237].

Though resveratrol illustrates potent anti-breast-cancer activity by regulating a number of significant pathways, it needs more attentions regarding the improvement of bioavailability, as it shows less oral absorption rate [238, 239]. Furthermore, the chemopreventive action of resveratrol still needs to be confirmed by future clinical trials; also a vast amount of clinical data is necessary to understand the therapeutic potential of resveratrol, and more study is needed to develop its derivatives that provide better bioavailability and is effective in different types of breast cancer patient [240, 241].

Apart from the above-mentioned natural compounds, there are some other chemical compounds currently being focused on and investigated for their promising chemopreventive potential in breast cancer. Similarly, silibinin is a flavonolignan, extracted from milk thistle (Silybum marianum), and has been reported to provoke autophagic cell death in breast cancer cells by downregulating the Bcl-2 expression and upregulation of Atg12-Atg5 formation and enhancing beclin-1 expression [149]. Karimi et al. [242] Represented that silibinin exhibits cytotoxic activity in breast cancer cell line through reducing the expression of ER $\alpha$. The anticancer activity of silibinin is associated with the suppression Wnt/LRP6 signaling [150] and also downregulates the TPA-induced MMP-9 expression through inhibiting COX-2 expression in breast cancer cells [151]. In adjuvant therapy, silibinin is reported to increase the efficacy of cisplatin and paclitaxel in MCF-7 breast cancer cells [152] and also to sensitize the chemoresistant breast cancer cells [153]. Similarly, quercetin glycoside such as quercetin $3-\mathrm{O}-\beta$-d-rutinoside (rutin) is reported to promote apoptosis in breast cancer cell line, while restoring the chemosensitivity in HER2-negative and triple-negative breast cancer cell lines [168]. Elsayed et al. [169] reported that rutin inhibits c-Met kinase activity in TNBC cell line and also significantly reduces the growth of TNBC MDA-MB-231/GFP orthotopic xenograft in nude mouse model at a dose of $30 \mathrm{mg} / \mathrm{kg}$. Emodin was reported to inhibit HER-2/neu tyrosine kinase activity in HER-2/neuoverexpressing cancer cells [99] and activates apoptosis through disruption of mitochondrial signaling pathway [243, 244]. In another study, it appeared that a natural phytocompound from rosemary, rosmarinic acid, inhibits breast cancer cell proliferation through reducing the COX-2 expression, AP-1 activation, and antagonized the ERK1/2 activation [166], while Wang et al. showed that rosmarinic acid suppresses interleukin-8 (IL-8) in the pathway of the NF- $\kappa$ B and thereby inhibits bone metastasis from breast carcinoma [167].

According to these studies, these phytochemicals have been shown potent to ameliorate the anticancer therapy in breast cancer (Table 1). However, more extensive studies are needed to conduct and authenticate these promising anticancer and chemopreventive compounds and their activities in clinical stage.

\section{Future Prospect of Herbal Management}

Presently the traditional treatment approaches that are being used for breast cancer treatment are being interrupted by a number of impediments mainly for the toxic effects accompanied by drug resistance. Chemotherapy or radiotherapy is creating a number of adverse effects in patients which are inevitable. Again due to drug resistance, the responses of these therapies become poor. In this case natural compounds from dietary sources can be blessings, in view of the fact that they can show synergistic action with many chemotherapeutics and can induce the efficacy of them. A number of natural compounds are reported to have a very positive outcome if taken with other medicines in breast cancer 


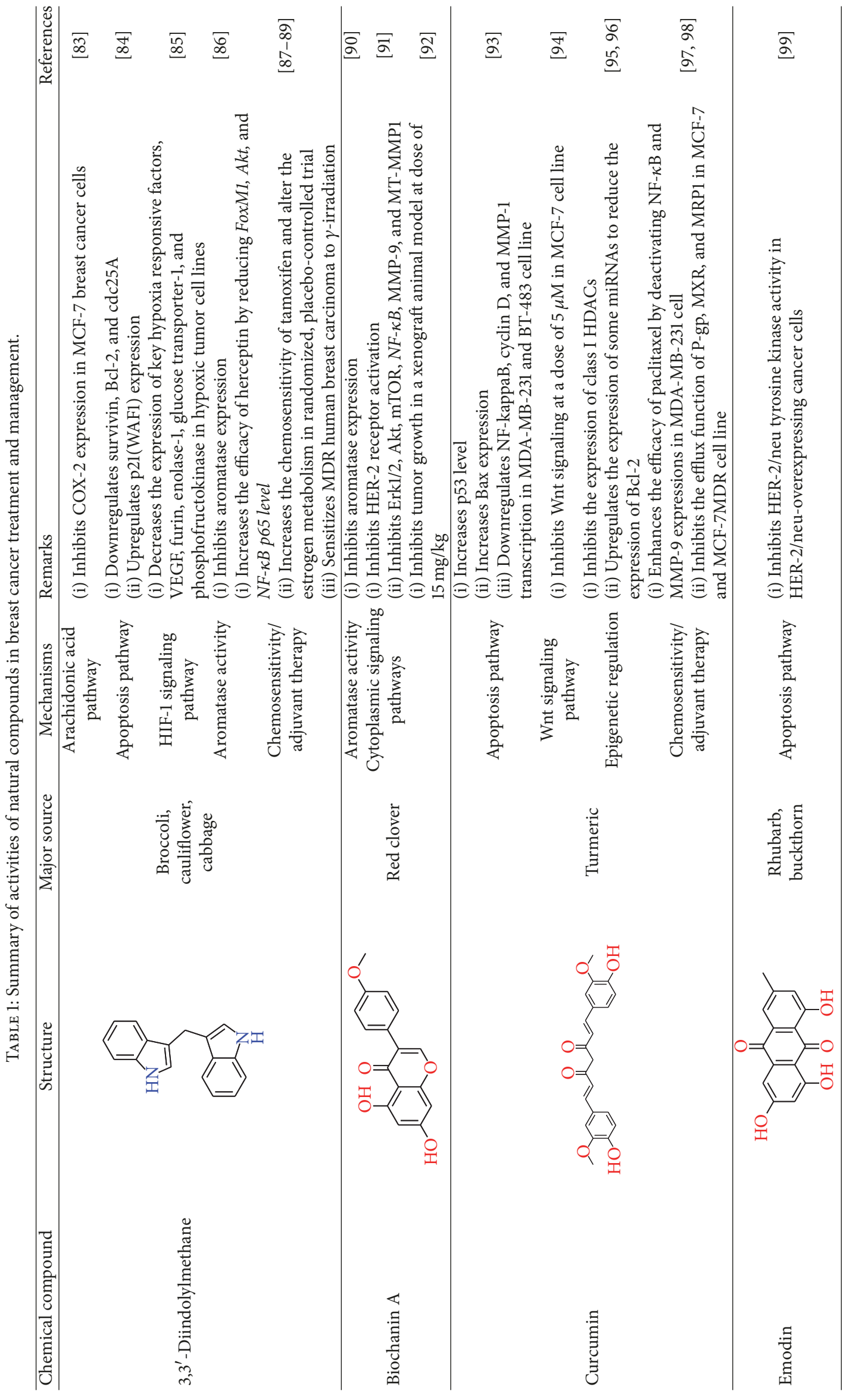




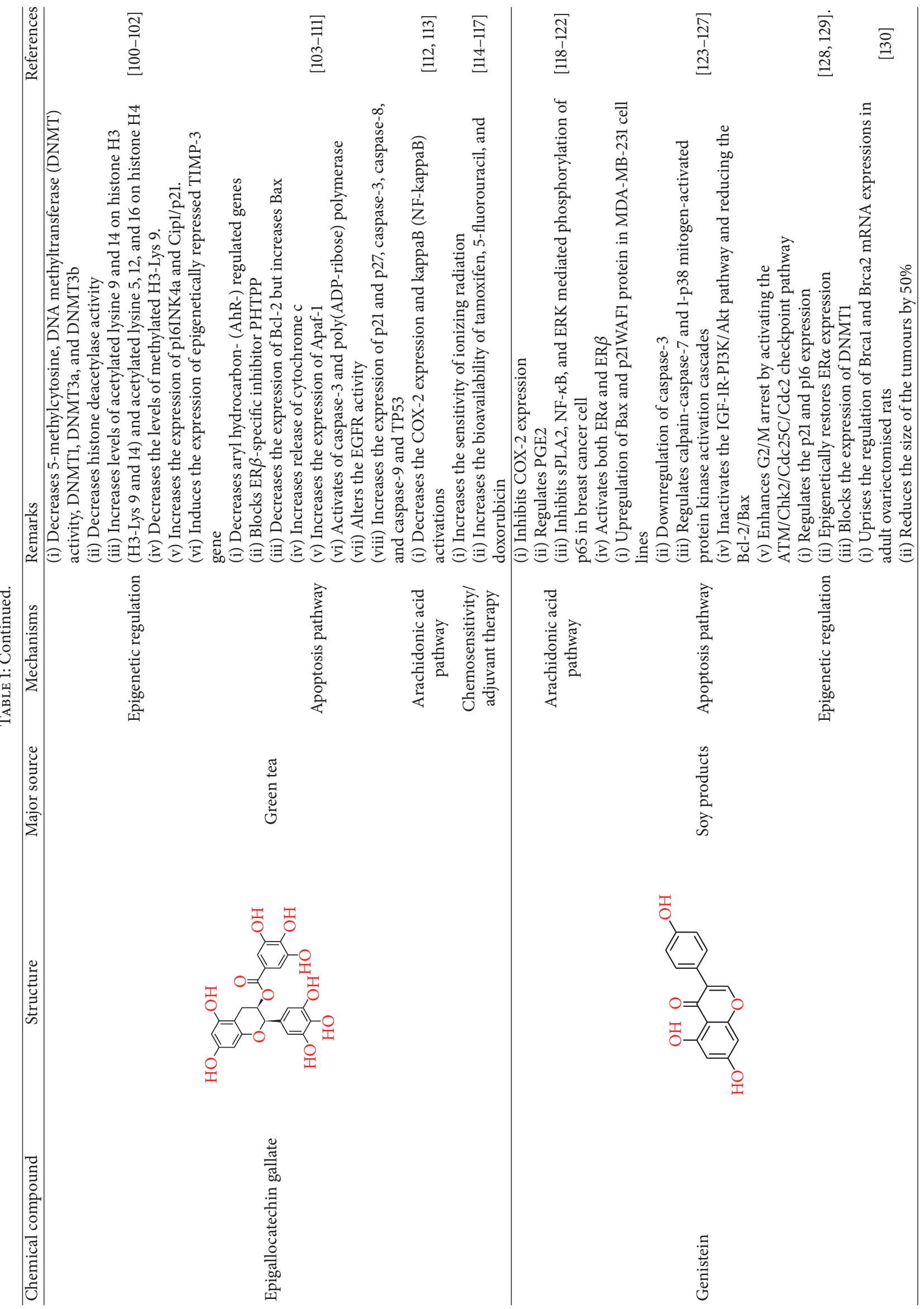




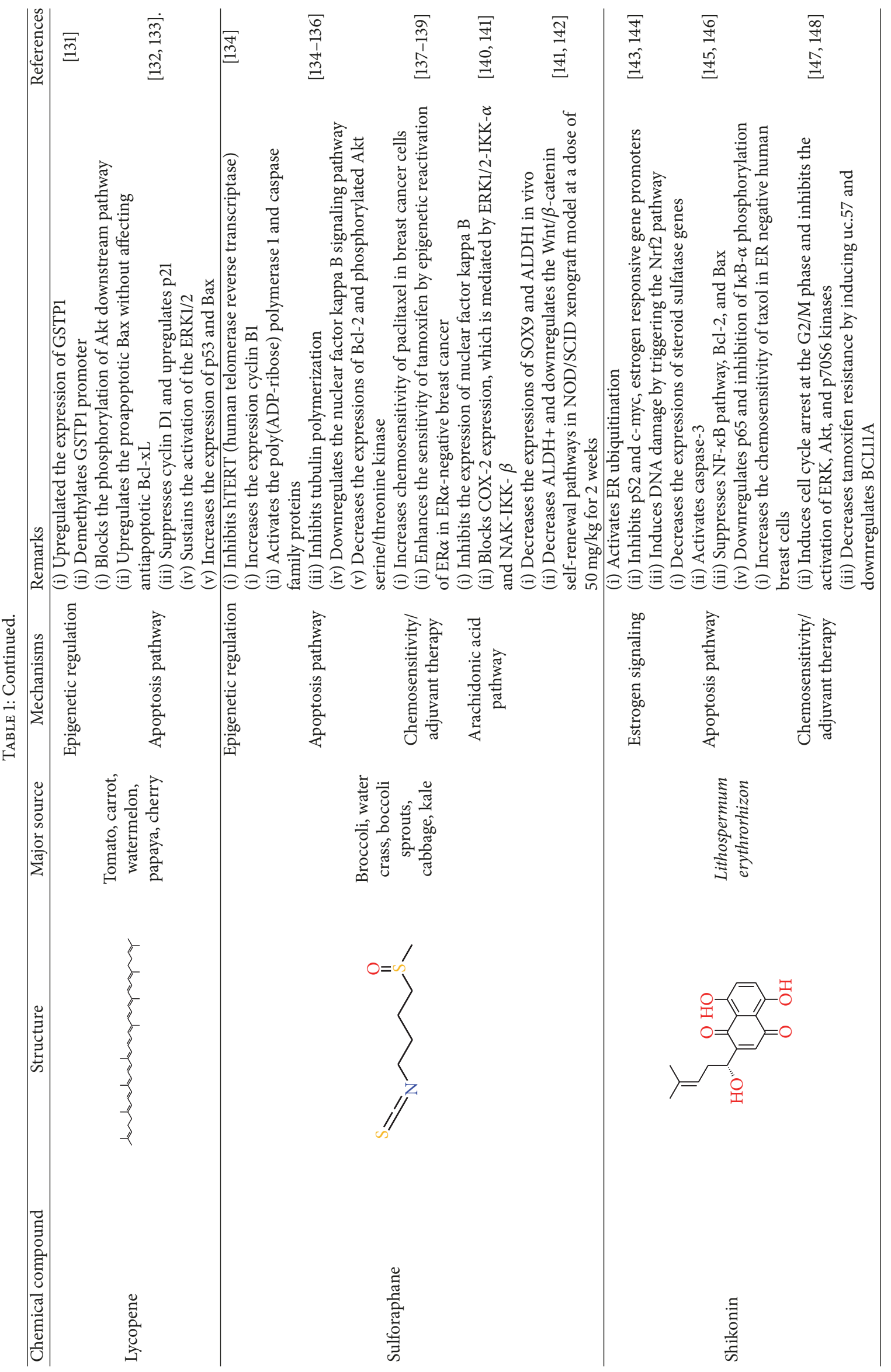




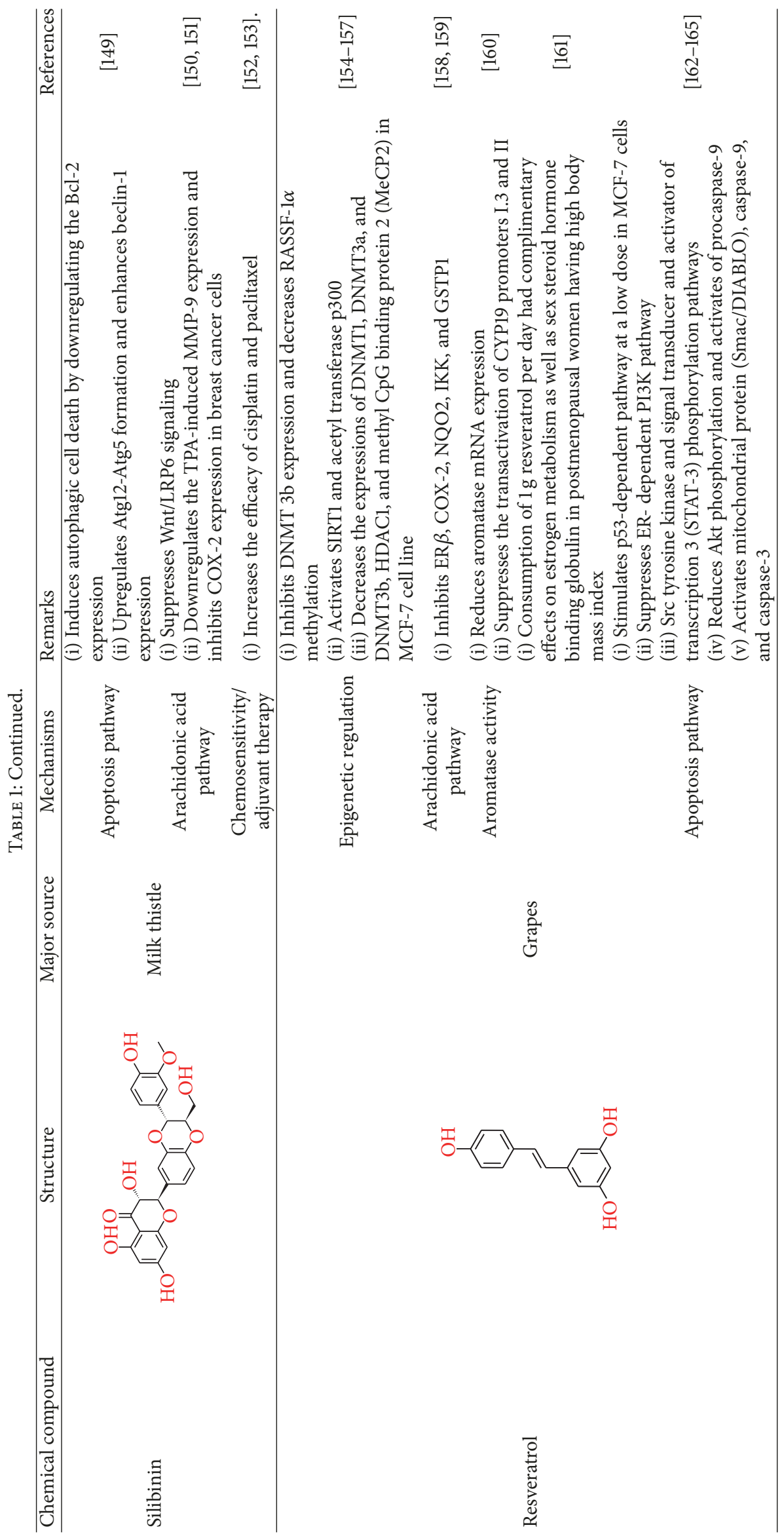




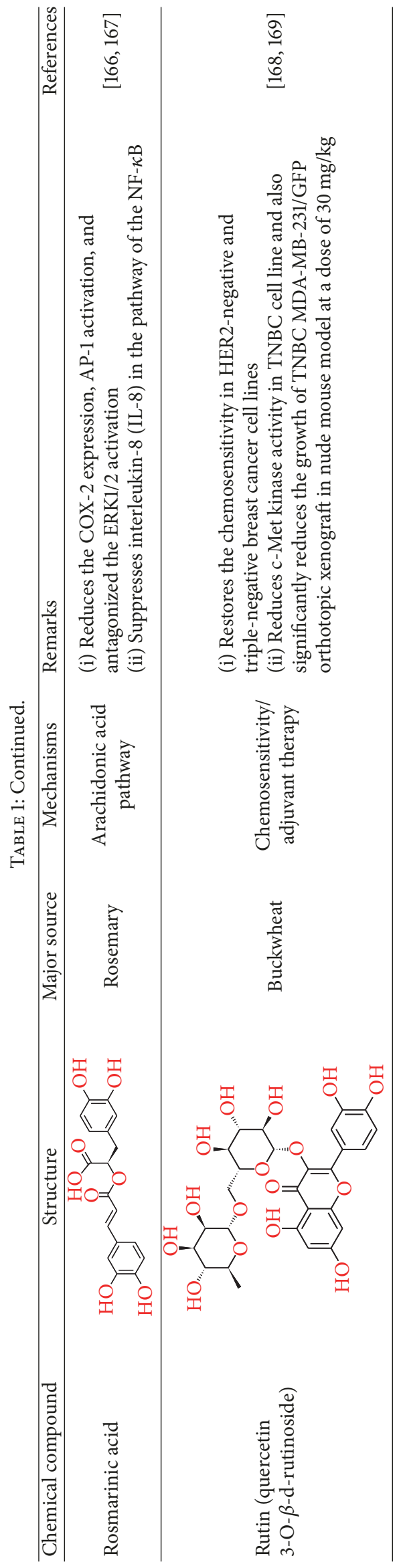


treatment. Following this strategy, a number of medicines and dietary components combination are reported. Among them some examples are combination of genistein and doxorubicin provides a synergistic effect [245], equol induces the efficacy of tamoxifen, pomegranate also reported to increase cell death and enhance tamoxifen-induced inhibition on cell viability [246], and DIM works synergistically with Paclitaxel and helps to induce apoptosis [247]. Rosemary extract can increase activity of anti-breast-cancer agent tamoxifen, trastuzumab, and paclitaxel [248]. These can be great fields for future research on natural compounds and can be a successful alternative approach for treating breast cancer.

Chemotherapy is the most popular and most important treatment strategy of cancer; however, there is a rising problem that patient can be unable to respond to chemotherapy due to chemoresistance [249]. This resistance can be developed by the activity of ATP-binding cassette (ABC) transporters that pump anticancer drugs out of the cells [250]. Hence a number of researchers are trying to find out natural compounds which act against multidrug resistance. $\beta$-elemene is a natural compound acting on MDR in human breast carcinoma MCF-7 and doxorubicin-resistant MCF-7 cells and can be a very promising agent for facing the problem of multidrug resistance [251]. Another research work reported that $3,3^{\prime}$-diindolylmethane (DIM) can function as a radio sensitizer to multidrug resistance breast cancer cells and eventually can fight against multidrug resistance [173]. So more research works on nature derived chemicals are necessary to find out their pathway and their possible role on acting against MDR.

The most aggressive subtype of breast cancer is triplenegative breast cancer and its treatment options are very limited as there is lack of a therapeutic target. Therefore, scientists are now trying to find out novel targets as well as alternative treatments for TNBC. A number of natural compounds are investigated and some of them showed satisfactory results. Curcumin and resveratrol are studied $[158,252]$ and it is evident that both of these compounds act effectively to treat TNBC and can also reduce side effects [253]. A natural compound EGCG, derived from green tea, is reported to block uncontrolled cell growth and can inhibit the migratory behavior of triple-negative breast cancer [254]. In a recent work, carnosol, a naturally occurring compound is reported to block cell cycle at G2 phase and also found to increase ROS-dependent apoptosis and beclin-1-independent autophagy in triple-negative MDA-MB-231 human breast cancer cells [255]. This proves that carnosol can be used to design a medicine for TNBC. Natural compounds can thus be used as a treatment system to fight TNBC.

In this review, some natural compounds are highlighted which are potent to modify any mechanism related to breast cancer. Nevertheless, there are some compounds which can act in more than one mechanism. As a result, they can show greater degree of efficacy. Again some of these compounds can show synergistic activity or they can work against multidrug resistance. By considering all these factors, it can be said that natural compounds can play a very promising role in treatment and prevention of breast cancer in near future if more deep studies are conducted.

\section{Conclusion}

The significance and contribution of natural derived compounds in the treatment and prevention of breast cancer is evident and cannot be ignored. The applications of the nature derived dietary chemicals are mostly widespread, and they are being practiced traditionally from a long time. More emphasis must be given on research works to optimize the activity of these compounds and to develop them as a therapeutic to treat the patient with breast cancer. These natural compounds can potentiate the activity of other traditional treatments and can also be used as a treatment system alone as they have the ability to modify different mechanisms. Apart from this, they play a strong role in preventing breast cancer. They can function by a number of pathways without initiating any kind of unusual toxic effect. In this review, the epigenetic mechanism, aromatase activity, arachidonic acid pathway, and apoptosis pathway are discussed and it is also evident that they have relationship with development of breast cancer. A number of natural compounds are highlighted in this work and their mode of action, pathway, synergistic action, and their future potential are widely discussed. Therefore, more detailed research works are required to confirm the appropriate role of these chemicals which can give us better understanding on their therapeutic use and can help us fight the existing challenges of breast cancer.

\section{Conflicts of Interest}

The authors declare that they have no conflicts of interest.

\section{References}

[1] S. S. Coughlin and D. U. Ekwueme, "Breast cancer as a global health concern,” Cancer Epidemiology, vol. 33, no. 5, pp. 315-318, 2009.

[2] J. Ferlay, C. Héry, P. Autier, and R. Sankaranarayanan, "Global burden of breast cancer," Breast Cancer Epidemiology, pp. 1-19, 2010.

[3] S. P. Helmrich, S. Shapiro, L. Rosenberg et al., "Risk factors for breast cancer," American Journal of Epidemiology, vol. 117, no. 1, pp. 35-45, 1983.

[4] Y. Li, S. Li, X. Meng, R.-Y. Gan, J.-J. Zhang, and H.-B. Li, "Dietary natural products for prevention and treatment of breast cancer," Nutrients, vol. 9, no. 7, article no. 728, 2017.

[5] A. Coates, S. Abraham, S. B. Kaye et al., "On the receiving endpatient perception of the side-effects of cancer chemotherapy," European Journal of Cancer and Clinical Oncology, vol. 19, no. 2, pp. 203-208, 1983.

[6] Early Breast Cancer Trialists' Collaborative Group, "Effects of radiotherapy and of differences in the extent of surgery for early breast cancer on local recurrence and 15-year survival: an overview of the randomized trial," The Lancet, vol. 366, pp. 2087-2106, 2005.

[7] L. A. Doyle, W. Yang, L. V. Abruzzo et al., "A multidrug resistance transporter from human MCF-7 breast cancer cells," Proceedings of the National Acadamy of Sciences of the United States of America, vol. 95, no. 26, pp. 15665-15670, 1998. 
[8] M. F. Ullah, "Cancer multidrug resistance (MDR): a major impediment to effective chemotherapy," Asian Pacific Journal of Cancer Prevention, vol. 9, no. 1, pp. 1-6, 2008.

[9] H. J. Burstein, S. Gelber, E. Guadagnoli, and J. C. Weeks, "Use of alternative medicine by women with early-stage breast cancer," The New England Journal of Medicine, vol. 340, no. 22, pp. 17331739, 1999.

[10] J. W. Henderson and R. J. Donatelle, "Complementary and alternative medicine use by women after completion of allopathic treatment for breast cancer," Alternative Therapies in Health and Medicine, vol. 10, no. 1, pp. 52-57, 2004.

[11] S. R. Adler and J. R. Fosket, "Disclosing complementary and alternative medicine use in the medical encounter: A qualitative study in women with breast cancer," Journal of Family Practice, vol. 48 , no. 6 , pp. 453-458, 1999.

[12] H. S. Boon, F. Olatunde, and S. M. Zick, "Trends in complementary/alternative medicine use by breast cancer survivors: Comparing survey data from 1998 and 2005," BMC Women's Health, vol. 7, article 4, 2007.

[13] B. Macmahon, P. Cole, and J. Brown, "Etiology of human breast cancer: A review2," Journal of the National Cancer Institute, vol. 50, no. 1, pp. 21-42, 1973.

[14] A. B. Miller and R. D. Bulbrook, "The epidemiology and etiology of breast cancer.," The New England Journal of Medicine, vol. 303, no. 21, pp. 1246-1248, 1980.

[15] M. C. Pike, D. V. Spicer, L. Dahmoush, and M. F. Press, "Estrogens, progestogens, normal breast cell proliferation, and breast cancer risk," Epidemiologic Reviews, vol. 15, no. 1, pp. 1730, 1993.

[16] K. Yamane, K. Tateishi, R. J. Klose et al., "PLU-1 Is an H3K4 Demethylase Involved in Transcriptional Repression and Breast Cancer Cell Proliferation," Molecular Cell, vol. 25, no. 6, pp. 801812, 2007.

[17] M. C. U. Cheang, D. Voduc, C. Bajdik et al., "Basal-like breast cancer defined by five biomarkers has superior prognostic value than triple-negative phenotype," Clinical Cancer Research, vol. 14, no. 5, pp. 1368-1376, 2008.

[18] M. Shoeb, "Anticancer agents from medicinal plants," Bangladesh Journal of Pharmacology, vol. 1, no. 2, pp. 35-41, 2008.

[19] D. J. Newman and G. M. Cragg, "Natural products as sources of new drugs from 1981 to 2014," Journal of Natural Products, vol. 79, no. 3, pp. 629-661, 2016.

[20] M. J. Balunas and A. D. Kinghorn, "Drug discovery from medicinal plants," Life Sciences, vol. 78, no. 5, pp. 431-441, 2005.

[21] G. M. Cragg and D. J. Newman, "Plants as a source of anticancer agents," Journal of Ethnopharmacology, vol. 100, no. 1-2, pp. 72-79, 2005.

[22] J. Burns, T. Yokota, H. Ashihara, M. E. J. Lean, and A. Crozier, "Plant foods and herbal sources of resveratrol," Journal of Agricultural and Food Chemistry, vol. 50, no. 11, pp. 3337-3340, 2002.

[23] D. R. A. Mans, A. B. da Rocha, and G. Schwartsmann, "Anticancer drug discovery and development in Brazil: targeted plant collection as a rational strategy to acquire candidate anti-cancer compounds," The Oncologist, vol. 5, no. 3, pp. 185-198, 2000.

[24] S. Somasundaram, N. A. Edmund, D. T. Moore, G. W. Small, Y. Y. Shi, and R. Z. Orlowski, "Dietary curcumin inhibits chemotherapy-induced apoptosis in models of human breast cancer," Cancer Research, vol. 62, no. 13, pp. 3868-3875, 2002.

[25] K. Sak, "Chemotherapy and dietary phytochemical agents," Chemotherapy Research and Practice, vol. 2012, Article ID 282570, 11 pages, 2012.
[26] C. M. Perou, T. Sørile, M. B. Eisen et al., "Molecular portraits of human breast tumours," Nature, vol. 406, no. 6797, pp. 747-752, 2000.

[27] T. Sørlie, C. M. Perou, and R. Tibshirani, "Gene expression patterns of breast carcinomas distinguish tumor subclasses with clinical implications," Proceedings of the National Acadamy of Sciences of the United States of America, vol. 98, no. 19, pp. 1086910874, 2001.

[28] A. Prat, J. S. Parker, O. Karginova et al., "Phenotypic and molecular characterization of the claudin-low intrinsic subtype of breast cancer," Breast Cancer Research, vol. 12, no. 5, article no. R68, 2010.

[29] B. D. Lehmann, J. A. Bauer, X. Chen et al., "Identification of human triple-negative breast cancer subtypes and preclinical models for selection of targeted therapies," The Journal of Clinical Investigation, vol. 121, no. 7, pp. 2750-2767, 2011.

[30] S. Nagini, "Breast cancer: Current molecular therapeutic targets and new players," Anti-Cancer Agents in Medicinal Chemistry, vol. 17, no. 2, pp. 152-163, 2017.

[31] J. I. Herschkowitz, K. Simin, V. J. Weigman et al., "Identification of conserved gene expression features between murine mammary carcinoma models and human breast tumors," Genome Biology, vol. 8, no. 5, article R76, 2007.

[32] S. Mitra, MicroRNA Therapeutics in Triple Negative Breast Cancer, 2017.

[33] G. N. Hortobagyi, "Treatment of breast cancer," The New England Journal of Medicine, vol. 339, no. 14, pp. 974-984, 1998.

[34] K. L. Maughan, M. A. Lutterbie, and P. S. Ham, "Treatment of breast cancer," Chemotherapy, vol. 51, article 53, 2010.

[35] S. M. Pierce, A. Recht, T. I. Lingos et al., "Long-term radiation complications following conservative surgery (CS) and radiation therapy (RT) in patients with early stage breast cancer," International Journal of Radiation Oncology • Biology • Physics, vol. 23, no. 5, pp. 915-923, 1992.

[36] M. M. Gottesman, T. Fojo, and S. E. Bates, "Multidrug resistance in cancer: role of ATP-dependent transporters," Nature Reviews Cancer, vol. 2, no. 1, pp. 48-58, 2002.

[37] Z. E. Sauna, M. M. Smith, M. Müller, K. M. Kerr, and S. V. Ambudkar, "The mechanism of action of multidrug-resistancelinked P-glycoprotein," Journal of Bioenergetics and Biomembranes, vol. 33, no. 6, pp. 481-491, 2001.

[38] E. Rivera, "Implications of anthracycline-resistant and taxaneresistant metastatic breast cancer and new therapeutic options," The Breast Journal, vol. 16, no. 3, pp. 252-263, 2010.

[39] J. König, M. Hartel, A. T. Nies et al., "Expression and localization of human multidrug resistance protein (ABCC) family members in pancreatic carcinoma," International Journal of Cancer, vol. 115, no. 3, pp. 359-367, 2005.

[40] P. Fumoleau, R. Largillier, C. Clippe et al., "Multicentre, phase II study evaluating capecitabine monotherapy in patients with anthracycline- and taxane-pretreated metastatic breast cancer," European Journal of Cancer, vol. 40, no. 4, pp. 536-542, 2004.

[41] X. Jiang, Y. Zhao, C. Smith et al., "Chronic myeloid leukemia stem cells possess multiple unique features of resistance to BCRABL targeted therapies," Leukemia, vol. 21, no. 5, pp. 926-935, 2007.

[42] R. R. Love, H. Leventhal, D. V. Easterling, and D. R. Nerenz, "Side effects and emotional distress during cancer chemotherapy," Cancer, vol. 63, no. 3, pp. 604-612, 1989.

[43] S. N. Saldanha and T. O. Tollefsbol, "The role of nutraceuticals in chemoprevention and chemotherapy and their clinical outcomes," Journal of Oncology, Article ID 192464, 2012. 
[44] G.-S. Liao, M. K. Apaya, and L.-F. Shyur, "Herbal medicine and acupuncture for breast cancer palliative care and adjuvant therapy," Evidence-Based Complementary and Alternative Medicine, vol. 2013, Article ID 437948, 2013.

[45] J. Zheng, Y. Zhou, Y. Li, D.-P. Xu, S. Li, and H.-B. Li, "Spices for prevention and treatment of cancers," Nutrients, vol. 8, no. 8, article no. 495, 2016.

[46] Y. Zhou, J. Zheng, Y. Li et al., "Natural polyphenols for prevention and treatment of cancer," Nutrients, vol. 8, no. 8, article no. 515, 2016.

[47] G. Grosso, F. Bella, J. Godos et al., "Possible role of diet in cancer: systematic review and multiple meta-analyses of dietary patterns, lifestyle factors, and cancer risk," Nutrition Reviews, vol. 75, no. 6, pp. 405-419, 2017.

[48] F. Li, S. Li, H.-B. Li, G.-F. Deng, W.-H. Ling, and X.-R. Xu, "Antiproliferative activities of tea and herbal infusions," Food \& Function, vol. 4, no. 4, pp. 530-538, 2013.

[49] M. Ducasse and M. A. Brown, "Epigenetic aberrations and cancer," Molecular Cancer, vol. 5, article no. 60, 2005.

[50] P. A. Jones and S. B. Baylin, "The epigenomics of cancer," Cell, vol. 128, no. 4, pp. 683-692, 2007.

[51] V. Stearns, Q. Zhou, and N. E. Davidson, "Epigenetic regulation as a new target for breast cancer therapy," Cancer Investigation, vol. 25, no. 8, pp. 659-665, 2007.

[52] M. B. Lustberg and B. Ramaswamy, "Epigenetic targeting in breast cancer: Therapeutic impact and future direction," Drug News \& Perspectives, vol. 22, no. 7, pp. 369-381, 2009.

[53] C. Basse and M. Arock, "The increasing roles of epigenetics in breast cancer: Implications for pathogenicity, biomarkers, prevention and treatment," International Journal of Cancer, vol. 137, no. 12, pp. 2785-2794, 2015.

[54] V. S. Thakur, G. Deb, M. A. Babcook, and S. Gupta, "Plant phytochemicals as epigenetic modulators: role in cancer chemoprevention," The AAPS Journal, vol. 16, no. 1, pp. 151-163, 2014.

[55] S. I. Khan, P. Aumsuwan, I. A. Khan, L. A. Walker, and A. K. Dasmahapatra, "Epigenetic events associated with breast cancer and their prevention by dietary components targeting the epigenome," Chemical Research in Toxicology, vol. 25, no. 1, pp. 61-73, 2012.

[56] K. R. Landis-Piwowar, V. Milacic, and Q. P. Dou, "Relationship between the methylation status of dietary flavonoids and their growth-inhibitory and apoptosis-inducing activities in human cancer cells," Journal of Cellular Biochemistry, vol. 105, no. 2, pp. 514-523, 2008.

[57] R. Aggarwal, M. Jha, A. Shrivastava, and A. K. Jha, "Natural compounds: Role in reversal of epigenetic changes," Biochemistry (Moscow), vol. 80, no. 8, article no. 125, pp. 972-989, 2015.

[58] R. T. Chlebowski, "Current concepts in breast cancer chemoprevention," Polish Archives of Internal Medicine, vol. 124, no. 4, pp. 191-199, 2014.

[59] E. Ko and A. Moon, "Natural Products for Chemoprevention of Breast Cancer," Journal of Cancer Prevention, vol. 20, no. 4, pp. 223-231, 2015.

[60] M. Maggiolini, D. Bonofiglio, V. Pezzi et al., "Aromatase overexpression enhances the stimulatory effects of adrenal androgens on MCF7 breast cancer cells," Molecular and Cellular Endocrinology, vol. 193, no. 1-2, pp. 13-18, 2002.

[61] E. D. Lephart, "Modulation of aromatase by phytoestrogens," Enzyme Research, vol. 2015, Article ID 594656, 2015.

[62] N. S. Yarla, A. Bishayee, G. Sethi et al., "Targeting arachidonic acid pathway by natural products for cancer prevention and therapy," Seminars in Cancer Biology, vol. 40, pp. 48-81, 2016.
[63] D. Wang and R. N. Dubois, "Eicosanoids and cancer," Nature Reviews Cancer, vol. 10, no. 3, pp. 181-193, 2010.

[64] M. Cuendet and J. M. Pezzuto, "The role of cyclooxygenase and lipoxygenase in cancer chemoprevention," Drug Metabolism and Drug Interactions, vol. 17, no. 1-4, pp. 109-157, 2000.

[65] C. Denkert, K.-J. Winzer, B.-M. Müller et al., "Elevated expression of cyclooxygenase-2 is a negative prognostic factor for disease free survival and overall survival in patients with breast carcinoma," Cancer, vol. 97, no. 12, pp. 2978-2987, 2003.

[66] G. S. Ranger, V. Thomas, A. Jewell, and K. Mokbel, "Elevated cyclooxygenase-2 expression correlates with distant metastases in breast cancer," Anticancer Reseach, vol. 24, no. 4, pp. 23492351, 2004.

[67] I. Stasinopoulos, D. R. O’Brien, F. Wildes, K. Glunde, and Z. M. Bhujwalla, "Silencing of cyclooxygenase-2 inhibits metastasis and delays tumor onset of poorly differentiated metastatic breast cancer cells," Molecular Cancer Research, vol. 5, no. 5, pp. 435-442, 2007.

[68] T. Borin, K. Angara, M. Rashid, B. Achyut, and A. Arbab, "Arachidonic Acid Metabolite as a Novel Therapeutic Target in Breast Cancer Metastasis," International Journal of Molecular Sciences, vol. 18, no. 12, p. 2661, 2017.

[69] S. Chumsri, T. Howes, T. Bao, G. Sabnis, and A. Brodie, "Aromatase, aromatase inhibitors, and breast cancer," The Journal of Steroid Biochemistry and Molecular Biology, vol. 125, no. 1-2, pp. 13-22, 2011.

[70] S. Sun, N. Hail Jr., and R. Lotan, "Apoptosis as a novel target for cancer chemoprevention," Journal of the National Cancer Institute, vol. 96, no. 9, pp. 662-672, 2004.

[71] R. W. Johnstone, A. A. Ruefli, and S. W. Lowe, "Apoptosis: a link between cancer genetics and chemotherapy," Cell, vol. 108, no. 2, pp. 153-164, 2002.

[72] J.-J. Liu, M. Lin, J.-Y. Yu, B. Liu, and J.-K. Bao, "Targeting apoptotic and autophagic pathways for cancer therapeutics," Cancer Letters, vol. 300, no. 2, pp. 105-114, 2011.

[73] L. R. Thomas, A. Henson, J. C. Reed, F. R. Salsbury, and A. Thorburn, "Direct binding of Fas-associated death domain (FADD) to the tumor necrosis factor-related apoptosis-inducing ligand receptor DR5 is regulated by the death effector domain of FADD," The Journal of Biological Chemistry, vol. 279, no. 31, pp. 32780-32785, 2004.

[74] N. Harper, M. Hughes, M. MacFarlane, and G. M. Cohen, "Fas-associated death domain protein and caspase- 8 are not recruited to the tumor necrosis factor receptor I signaling complex during tumor necrosis factor-induced apoptosis," The Journal of Biological Chemistry, vol. 278, no. 28, pp. 2553425541, 2003.

[75] M. E. Guicciardi and G. J. Gores, "Life and death by death receptors," The FASEB Journal, vol. 23, no. 6, pp. 1625-1637, 2009.

[76] H. Wajant, "Death receptors," Essays in Biochemistry, vol. 39, pp. 53-71, 2003.

[77] D. R. Green, "Apoptotic pathways: paper wraps stone blunts scissors," Cell, vol. 102, no. 1, pp. 1-4, 2000.

[78] M. H. Kang and C. P. Reynolds, "BcI-2 Inhibitors: targeting mitochondrial apoptotic pathways in cancer therapy," Clinical Cancer Research, vol. 15, no. 4, pp. 1126-1132, 2009.

[79] T. Kuno, T. Tsukamoto, A. Hara, and T. Tanaka, "Cancer chemoprevention through the induction of apoptosis by natural compounds," Journal of Biophysical Chemistry, vol. 3, no. 2, pp. 156-173, 2012. 
[80] W. Roth and J. C. Reed, "Apoptosis and cancer: When Bax is TRAILing away," Nature Medicine, vol. 8, no. 3, pp. 216-218, 2002.

[81] S. Dall'acqua, "Natural products as antimitotic agents," Current Topics in Medicinal Chemistry, vol. 14, no. 20, pp. 2272-2285, 2014.

[82] H. Liu, X. Chen, J. Sun et al., "The efficacy and toxicity of paclitaxel plus S-1 compared with paclitaxel plus 5-FU for advanced gastric cancer: a PRISMA systematic review and meta-analysis of randomized controlled trials," Medicine, vol. 93, no. 25, p. e164, 2014.

[83] S. C. Degner, A. J. Papoutsis, O. Selmin, and D. F. Romagnolo, "Targeting of aryl hydrocarbon receptor-mediated activation of cyclooxygenase- 2 expression by the indole-3-carbinol metabolite 3,3 -diindolylmethane in breast cancer cells 1,2," Journal of Nutrition, vol. 139, no. 1, pp. 26-32, 2009.

[84] K. M. W. Rahman, Y. Li, Z. Wang, S. H. Sarkar, and F. H. Sarkar, "Gene expression profiling revealed survivin as a target of 3,3/diindolylmethane-induced cell growth inhibition and apoptosis in breast cancer cells," Cancer Research, vol. 66, no. 9, pp. 49524960, 2006.

[85] J. E. Riby, G. L. Firestone, and L. F. Bjeldanes, “3,3/-Diindolylmethane reduces levels of HIF- $1 \alpha$ and HIF-1 activity in hypoxic cultured human cancer cells," Biochemical Pharmacology, vol. 75, no. 9, pp. 1858-1867, 2008.

[86] B. E. Licznerska, H. Szaefer, M. Murias, A. Bartoszek, and W. Baer-Dubowska, "Modulation of CYP19 expression by cabbage juices and their active components: Indole-3-carbinol and 3,3/-diindolylmethene in human breast epithelial cell lines," European Journal of Nutrition, vol. 52, no. 5, pp. 1483-1492, 2013.

[87] A. Ahmad, S. Ali, A. Ahmed et al., “3, 3'-Diindolylmethane enhances the effectiveness of herceptin against HER-2/neuexpressing breast cancer cells," PLOS ONE, vol. 8, no. 1, Article ID e54657, 2013.

[88] A. Ahmad, S. Ali, Z. Wang et al., “3, 3'-diindolylmethane enhances taxotere-induced growth inhibition of breast cancer cells through downregulation of FoxM1," International Journal of Cancer, vol. 129, no. 7, pp. 1781-1791, 2011.

[89] C. A. Thomson, H. H. S. Chow, B. C. Wertheim et al., "A randomized, placebo-controlled trial of diindolylmethane for breast cancer biomarker modulation in patients taking tamoxifen," Breast Cancer Research and Treatment, vol. 165, no. 1, pp. 97-107, 2017.

[90] Y. Wang, W. M. Gho, F. I. Chan, S. Chen, and L. K. Leung, "The red clover (Trifolium pratense) isoflavone biochanin A inhibits aromatase activity and expression," British Journal of Nutrition, vol. 99, no. 2, pp. 303-310, 2008.

[91] A. Bhushan, V. Sehdev, and J. C. K. Lai, "Biochanin A modulates cell viability, invasion, and growth promoting signaling pathways in HER-2-positive breast cancer cells," Journal of Oncology, Article ID 121458, 2009.

[92] Y. J. Moon, B. S. Shin, G. An, and M. E. Morris, "Biochanin A inhibits breast cancer tumor growth in a murine xenograft model," Pharmaceutical Research, vol. 25, no. 9, pp. 2158-2163, 2008.

[93] Q. Liu, W. T. Y. Loo, S. C. W. Sze, and Y. Tong, "Curcumin inhibits cell proliferation of MDA-MB-231 and BT- 483 breast cancer cells mediated by down-regulation of $\mathrm{NF} \kappa \mathrm{B}$, cyclinD and MMP-1 transcription," Phytomedicine, vol. 16, no. 10, pp. 916922, 2009.

[94] M. Kakarala, D. E. Brenner, H. Korkaya et al., “Targeting breast stem cells with the cancer preventive compounds curcumin and piperine," Breast Cancer Research and Treatment, vol. 122, no. 3, pp. 777-785, 2010.

[95] Y. Chen, W. Shu, W. Chen, Q. Wu, H. Liu, and G. Cui, "Curcumin, both histone deacetylase and p300/CBP-specific inhibitor, represses the activity of nuclear factor kappa B and Notch 1 in Raji cells," Basic \& Clinical Pharmacology \& Toxicology, vol. 101, no. 6, pp. 427-433, 2007.

[96] J. Yang, Y. Cao, J. Sun, and Y. Zhang, "Curcumin reduces the expression of Bcl-2 by upregulating miR-15a and miR-16 in MCF-7 cells," Medical Oncology, vol. 27, no. 4, pp. 1114-1118, 2010.

[97] B. B. Aggarwal, S. Shishodia, Y. Takada et al., "Curcumin suppresses the paclitaxel-induced nuclear factor- $\kappa \mathrm{B}$ pathway in breast cancer cells and inhibits lung metastasis of human breast cancer in nude mice," Clinical Cancer Research, vol. 11, no. 20, pp. 7490-7498, 2005.

[98] P. Limtrakul, W. Chearwae, S. Shukla, C. Phisalphong, and S. V. Ambudkar, "Modulation of function of three ABC drug transporters, $\mathrm{P}$-glycoprotein $(\mathrm{ABCB} 1)$, mitoxantrone resistance protein $(\mathrm{ABCG})$ and multidrug resistance protein 1 (ABCC1) by tetrahydrocurcumin, a major metabolite of curcumin," Molecular and Cellular Biochemistry, vol. 296, no. 1-2, pp. 8595, 2007.

[99] L. Zhang, M.-C. Hung, C.-J. Chang, and S. S. Bacus, "Suppressed Transformation and Induced Differentiation of HER2/neu-overexpressing Breast Cancer Cells by Emodin," Cancer Research, vol. 55, no. 17, pp. 3890-3896, 1995.

[100] C. Berner, E. Aumüller, A. Gnauck, M. Nestelberger, A. Just, and A. G. Haslberger, "Epigenetic control of estrogen receptor expression and tumor suppressor genes is modulated by bioactive food compounds," Annals of Nutrition and Metabolism, vol. 57, no. 3-4, pp. 183-189, 2011.

[101] V. Nandakumar, M. Vaid, and S. K. Katiyar, “(-)-Epigallocatechin-3-gallate reactivates silenced tumor suppressor genes, Cip1/p21 and p16INK4a, by reducing DNA methylation and increasing histones acetylation in human skin cancer cells," Carcinogenesis, vol. 32, no. 4, pp. 537-544, 2011.

[102] G. Deb, V. S. Thakur, A. M. Limaye, and S. Gupta, "Epigenetic induction of tissue inhibitor of matrix metalloproteinase-3 by green tea polyphenols in breast cancer cells," Molecular Carcinogenesis, vol. 54, no. 6, pp. 485-499, 2015.

[103] S. G. Han, S.-S. Han, M. Toborek, and B. Hennig, "EGCG protects endothelial cells against PCB 126-induced inflammation through inhibition of AhR and induction of Nrf2-regulated genes," Toxicology and Applied Pharmacology, vol. 261, no. 2, pp. 181-188, 2012.

[104] A. M. Roy, M. S. Baliga, and S. K. Katiyar, "Epigallocatechin-3gallate induces apoptosis in estrogen receptor-negative human breast carcinoma cells via modulation in protein expresssion of p53 and Bax and caspase-3 activation," Molecular Cancer Therapeutics, vol. 4, no. 1, pp. 81-90, 2005.

[105] Y.-C. Hsu and Y.-M. Liou, "The anti-cancer effects of (-)Epigalocathine-3-gallate on the signaling pathways associated with membrane receptors in MCF-7 cells," Journal of Cellular Physiology, vol. 226, no. 10, pp. 2721-2730, 2011.

[106] O.-Y. Hong, E.-M. Noh, H.-Y. Jang et al., "Epigallocatechin gallate inhibits the growth of MDA-MB-231 breast cancer cells via inactivation of the $\beta$-Catenin signaling pathway," Oncology Letters, vol. 14, no. 1, pp. 441-446, 2017. 
[107] K. Chisholm, B. J. Bray, and R. J. Rosengren, “Tamoxifen and epigallocatechin gallate are synergistically cytotoxic to MDAMB-231 human breast cancer cells," Anti-Cancer Drugs, vol. 15, no. 9, pp. 889-897, 2004.

[108] F. Farabegoli, A. Papi, and M. Orlandi, “(-)-Epigallocatechin-3gallate down-regulates EGFR, MMP-2, MMP-9 and EMMPRIN and inhibits the invasion of MCF-7 tamoxifen-resistant cells," Bioscience Reports, vol. 31, no. 2, pp. 99-108, 2011.

[109] M. Masuda, M. Suzui, J. T. E. Lim, A. Deguchi, J.-W. Soh, and I. B. Weinstein, "Epigallocatechin-3-gallate decreases VEGF production in head and neck and breast carcinoma cells by inhibiting EGFR-related pathways of signal transduction," Journal of Experimental Therapeutics and Oncology, vol. 2, no. 6, pp. 350-359, 2002.

[110] S. Islam, N. Islam, T. Kermode et al., "Involvement of caspase3 in epigallocatechin-3-gallate-mediated apoptosis of human chondrosarcoma cells," Biochemical and Biophysical Research Communications, vol. 270, no. 3, pp. 793-797, 2000.

[111] M.-J. Li, Y.-C. Yin, J. Wang, and Y.-F. Jiang, "Green tea compounds in breast cancer prevention and treatment," World Journal of Clinical Oncology, vol. 5, no. 3, pp. 520-528, 2014.

[112] G. Peng, D. A. Dixon, S. J. Muga, T. J. Smith, and M. J. Wargovich, "Green tea polyphenol (-)-epigallocatechin-3-gallate inhibits cyclooxygenase-2 expression in colon carcinogenesis," Molecular Carcinogenesis, vol. 45, no. 5, pp. 309-319, 2006.

[113] K.-S. Chun and Y.-J. Surh, "Cancer Chemoprevention Targeting COX-2 using Dietary Phytochemicals," Cancer and Inflammation Mechanisms: Chemical, Biological, and Clinical Aspects, pp. 339-353, 2014.

[114] G. Zhang, Y. Wang, Y. Zhang et al., "Anti-cancer activities of tea epigallocatechin-3-gallate in breast cancer patients under radiotherapy," Current Molecular Medicine, vol. 12, no. 2, pp. 163-176, 2012.

[115] S.-C. Shin and J.-S. Choi, "Effects of epigallocatechin gallate on the oral bioavailability and pharmacokinetics of tamoxifen and its main metabolite, 4-hydroxytamoxifen, in rats," Anti-Cancer Drugs, vol. 20, no. 7, pp. 584-588, 2009.

[116] J. Qiao, C. Gu, W. Shang et al., "Effect of green tea on pharmacokinetics of 5-fluorouracil in rats and pharmacodynamics in human cell lines in vitro," Food and Chemical Toxicology, vol. 49, no. 6, pp. 1410-1415, 2011.

[117] M. E. Stearns, M. D. Amatangelo, D. Varma, C. Sell, and S. M. Goodyear, "Combination therapy with epigallocatechin3-gallate and doxorubicin in human prostate tumor modeling studies: Inhibition of metastatic tumor growth in severe combined immunodeficiency mice," The American Journal of Pathology, vol. 177, no. 6, pp. 3169-3179, 2010.

[118] S. Banerjee, Y. Li, Z. Wang, and F. H. Sarkar, "Multi-targeted therapy of cancer by genistein," Cancer Letters, vol. 269, no. 2, pp. 226-242, 2008.

[119] K. K. Dharmappa, R. Mohamed, H. V. Shivaprasad, and B. S. Vishwanath, "Genistein, a potent inhibitor of secretory phospholipase A2: A new insight in down regulation of inflammation," Inflammopharmacology, vol. 18, no. 1, pp. 25-31, 2010.

[120] T. Y. Lau and L. K. Leung, "Soya isoflavones suppress phorbol 12-myristate 13-acetate-induced COX-2 expression in MCF-7 cells," British Journal of Nutrition, vol. 96, no. 1, pp. 169-176, 2006.

[121] M.-H. Chung, D.-H. Kim, H.-K. Na et al., "Genistein inhibits phorbol ester-induced NF- $\kappa$ B transcriptional activity and COX2 expression by blocking the phosphorylation of p65/RelA in human mammary epithelial cells," Mutation Research Fundamental and Molecular Mechanisms of Mutagenesis, vol. 768, no. C, pp. 74-83, 2014.

[122] D. G. Pons, M. Nadal-Serrano, M. M. Blanquer-Rossello, J. Sastre-Serra, J. Oliver, and P. Roca, "Genistein modulates proliferation and mitochondrial functionality in breast cancer cells depending on ERalpha/ERbeta ratio," Journal of Cellular Biochemistry, vol. 115, no. 5, pp. 949-958, 2014.

[123] Y. Li, S. Upadhyay, M. Bhuiyan, and F. H. Sarkar, "Induction of apoptosis in breast cancer cells MDA-MB-231 by genistein," Oncogene, vol. 18, no. 20, pp. 3166-3172, 1999.

[124] S. Yang, Q. Zhou, and X. Yang, "Caspase-3 status is a determinant of the differential responses to genistein between MDAMB-231 and MCF-7 breast cancer cells," Biochimica et Biophysica Acta (BBA) - Molecular Cell Research, vol. 1773, no. 6, pp. 903-911, 2007.

[125] H.-Y. Shim, J.-H. Park, H.-D. Paik, S.-Y. Nah, D. S. H. L. Kim, and Y. S. Han, "Genistein-induced apoptosis of human breast cancer MCF-7 cells involves calpain-caspase and apoptosis signaling kinase 1-p38 mitogen-activated protein kinase activation cascades," Anti-Cancer Drugs, vol. 18, no. 6, pp. 649-657, 2007.

[126] J. Chen, Y. Duan, X. Zhang, Y. Ye, B. Ge, and J. Chen, "Genistein induces apoptosis by the inactivation of the IGF-1R/p-Akt signaling pathway in MCF-7 human breast cancer cells," Food \& Function, vol. 6, no. 3, pp. 995-1000, 2015.

[127] X. Liu, C. Sun, X. Jin et al., "Genistein enhances the radiosensitivity of breast cancer cells via G2/M cell cycle arrest and apoptosis," Molecules, vol. 18, no. 11, pp. 13200-13217, 2013.

[128] Y. Li, H. Chen, T. M. Hardy, and T. O. Tollefsbol, "Epigenetic Regulation of Multiple Tumor-Related Genes Leads to Suppression of Breast Tumorigenesis by Dietary Genistein," PLoS ONE, vol. 8, no. 1, Article ID e54369, 2013.

[129] Q. Xie, Q. Bai, L. Zou et al., "Genistein inhibits DNA methylation and increases expression of tumor suppressor genes in human breast cancer cells," Genes, Chromosomes and Cancer, vol. 53, no. 5, pp. 422-431, 2014.

[130] Y. Tominaga, A. Wang, R.-H. Wang, X. Wang, L. Cao, and C.-X. Deng, "Genistein inhibits Brcal mutant tumor growth through activation of DNA damage checkpoints, cell cycle arrest, and mitotic catastrophe," Cell Death \& Differentiation, vol. 14, no. 3, pp. 472-479, 2007.

[131] A. King-Batoon, J. M. Leszczynska, and C. B. Klein, "Modulation of gene methylation by genistein or lycopene in breast cancer cells," Environmental and Molecular Mutagenesis, vol. 49, no. 1, pp. 36-45, 2008.

[132] M. Takeshima, M. Ono, T. Higuchi, C. Chen, T. Hara, and S. Nakano, "Anti-proliferative and apoptosis-inducing activity of lycopene against three subtypes of human breast cancer cell lines," Cancer Science, vol. 105, no. 3, pp. 252-257, 2014.

[133] S. J. Peng, J. Li, Y. Zhou et al., "In vitro effects and mechanisms of lycopene in MCF-7 human breast cancer cells," Genetics and Molecular Research, vol. 16, no. 2, Article ID gmr16029434, 2017.

[134] A. Pledgie-Tracy, M. D. Sobolewski, and N. E. Davidson, "Sulforaphane induces cell type-specific apoptosis in human breast cancer cell lines," Molecular Cancer Therapeutics, vol. 6, no. 3, pp. 1013-1021, 2007.

[135] S. J. T. Jackson and K. W. Singletary, "Sulforaphane inhibits human MCF-7 mammary cancer cell mitotic progression and tubulin polymerization," Journal of Nutrition, vol. 134, no. 9, pp. 2229-2236, 2004

[136] S. J. T. Jackson and K. W. Singletary, "Sulforaphane: A naturally occuring mammary carcinoma mitotic inhibitor, which 
disrupts tubulin polymerization," Carcinogenesis, vol. 25, no. 2, pp. 219-227, 2004.

[137] S.-H. Kim, H.-J. Park, and D.-O. Moon, "Sulforaphane sensitizes human breast cancer cells to paclitaxel-induced apoptosis by downregulating the NF- $\kappa \mathrm{B}$ signaling pathway," Oncology Letters, vol. 13, no. 6, pp. 4427-4432, 2017.

[138] A. Lewinska, D. Bednarz, J. Adamczyk-Grochala, and M. Wnuk, "Phytochemical-induced nucleolar stress results in the inhibition of breast cancer cell proliferation," Redox Biology, vol. 12, pp. 469-482, 2017.

[139] Y. Li, S. M. Meeran, and T. O. Tollefsbol, "Combinatorial bioactive botanicals re-sensitize tamoxifen treatment in ER-negative breast cancer via epigenetic reactivation of ER $\alpha$ expression," Scientific Reports, vol. 7, no. 1, article no. 9345, 2017.

[140] H.-N. Kim, D.-H. Kim, E.-H. Kim et al., "Sulforaphane inhibits phorbol ester-stimulated IKK-NF- $\kappa \mathrm{B}$ signaling and COX-2 expression in human mammary epithelial cells by targeting NF$\kappa \mathrm{B}$ activating kinase and ERK," Cancer Letters, vol. 351, no. 1, pp. 41-49, 2014.

[141] Q. Li, Y. Yao, G. Eades, Z. Liu, Y. Zhang, and Q. Zhou, "Downregulation of miR-140 promotes cancer stem cell formation in basal-like early stage breast cancer," Oncogene, vol. 33, no. 20, pp. 2589-2600, 2014.

[142] Y. Li, T. Zhang, H. Korkaya et al., "Sulforaphane, a dietary component of broccoli/broccoli sprouts, inhibits breast cancer stem cells," Clinical Cancer Research, vol. 16, no. 9, pp. 25802590, 2010.

[143] Y. Yao and Q. Zhou, "A novel antiestrogen agent Shikonin inhibits estrogen-dependent gene transcription in human breast cancer cells," Breast Cancer Research and Treatment, vol. 121, no. 1, pp. 233-240, 2010.

[144] Y. Yao, A. M. H. Brodie, N. E. Davidson, T. W. Kensler, and Q. Zhou, "Inhibition of estrogen signaling activates the NRF2 pathway in breast cancer," Breast Cancer Research and Treatment, vol. 124, no. 2, pp. 585-591, 2010.

[145] Y. Zhang, R.-Q. Qian, and P.-P. Li, "Shikonin, an ingredient of Lithospermum erythrorhizon, down-regulates the expression of steroid sulfatase genes in breast cancer cells," Cancer Letters, vol. 284, no. 1, pp. 47-54, 2009.

[146] N. Duru, R. Gernapudi, and Q. Zhou, "Chemopreventive activities of shikonin in breast cancer," Biochemistry \& Pharmacology, vol. 3, article e163, 2014.

[147] W. Li, J. Liu, K. Jackson, R. Shi, and Y. Zhao, "Sensitizing the therapeutic efficacy of taxol with shikonin in human breast cancer cells," PLoS ONE, vol. 9, no. 4, Article ID e94079, 2014.

[148] C. Zhang, J. Wang, L. Zhang et al., "Shikonin reduces tamoxifen resistance through long non-coding RNA uc.57," Oncotarget, vol. 8, no. 51, 2017.

[149] K. Jiang, W. Wang, X. Jin, Z. Wang, Z. Ji, and G. Meng, "Silibinin, a natural flavonoid, induces autophagy via ROS-dependent mitochondrial dysfunction and loss of ATP involving BNIP3 in human MCF7 breast cancer cells," Oncology Reports, vol. 33, no. 6, pp. 2711-2718, 2015.

[150] W. Lu, C. Lin, T. D. King, H. Chen, R. C. Reynolds, and Y. $\mathrm{Li}$, "Silibinin inhibits Wnt/ $\beta$-catenin signaling by suppressing Wnt co-receptor LRP6 expression in human prostate and breast cancer cells," Cellular Signalling, vol. 24, no. 12, pp. 2291-2296, 2012.

[151] S. Kim, S. H. Kim, S. M. Hur et al., "Silibinin prevents TPAinduced MMP-9 expression by down-regulation of COX-2 in human breast cancer cells," Journal of Ethnopharmacology, vol. 126, no. 2, pp. 252-257, 2009.
[152] H. Chavoshi, V. Vahedian, S. Saghaei, M. B. Pirouzpanah, M. Raeisi, and N. Samadi, "Adjuvant therapy with silibinin improves the efficacy of paclitaxel and cisplatin in MCF-7 breast cancer cells," Asian Pacific Journal of Cancer Prevention, vol. 18, no. 8, pp. 2243-2247, 2017.

[153] O. Molavi, F. Narimani, F. Asiaee et al., "Silibinin sensitizes chemo-resistant breast cancer cells to chemotherapy," Pharmaceutical Biology, vol. 55, no. 1, pp. 729-739, 2017.

[154] A. Bishayee, "Cancer prevention and treatment with resveratrol: from rodent studies to clinical trials," Cancer Prevention Research, vol. 2, no. 5, pp. 409-418, 2009.

[155] W. Qin, K. Zhang, K. Clarke, T. Weiland, and E. R. Sauter, "Methylation and miRNA effects of resveratrol on mammary tumors vs. normal tissue," Nutrition and Cancer, vol. 66, no. 2, pp. 270-277, 2014.

[156] R.-H. Wang, K. Sengupta, C. Li et al., "Impaired DNA Damage Response, Genome Instability, and Tumorigenesis in SIRT1 Mutant Mice," Cancer Cell, vol. 14, no. 4, pp. 312-323, 2008.

[157] B. Stefanska, H. Karlic, F. Varga, K. Fabianowska-Majewska, and A. G. Haslberger, "Epigenetic mechanisms in anti-cancer actions of bioactive food components-the implications in cancer prevention," British Journal of Pharmacology, vol. 167, no. 2, pp. 279-297, 2012.

[158] D. Sinha, N. Sarkar, J. Biswas, and A. Bishayee, "Resveratrol for breast cancer prevention and therapy: preclinical evidence and molecular mechanisms," Seminars in Cancer Biology, 2016.

[159] T. Hsieh and J. M. Wu, "Resveratrol: Biological and pharmaceutical properties as anticancer molecule," BioFactors, vol. 36, no. 5, pp. 360-369, 2010.

[160] Y. Wang, K. W. Lee, F. L. Chan, S. Chen, and L. K. Leung, "The red wine polyphenol resveratrol displays bilevel inhibition on aromatase in breast cancer cells," Toxicological Sciences, vol. 92, no. 1, pp. 71-77, 2006.

[161] H.-H. S. Chow, L. L. Garland, B. M. Heckman-Stoddard et al., "A pilot clinical study of resveratrol in postmenopausal women with high body mass index: Effects on systemic sex steroid hormones," Journal of Translational Medicine, vol. 12, no. 1, article no. 223, 2014.

[162] M. T. Laux, M. Aregullin, J. P. Berry, J. A. Flanders, and E. Rodriguez, "Identification of a p53-Dependent Pathway in the Induction of Apoptosis of Human Breast Cancer Cells by the Natural Product, Resveratrol," The Journal of Alternative and Complementary Medicine, vol. 10, no. 2, pp. 235-239, 2004.

[163] H. Kim, P. Hall, M. Smith et al., "Chemoprevention by Grape Seed Extract and Genistein in Carcinogen-induced Mammary Cancer in Rats Is Diet Dependent2," Journal of Nutrition, vol. 134, no. 12, pp. 3445S-3452S, 2004.

[164] Y. Li, J. Liu, X. Liu et al., "Resveratrol-induced cell inhibition of growth and apoptosis in MCF7 human breast cancer cells are associated with modulation of phosphorylated Akt and caspase9," Applied Biochemistry and Biotechnology, vol. 135, no. 3, pp. 181-192, 2006.

[165] D. Sareen, S. R. Darjatmoko, D. M. Albert, and A. S. Polans, "Mitochondria, calcium, and calpain are key mediators of resveratrol-induced apoptosis in breast cancer," Molecular Pharmacology, vol. 72, no. 6, pp. 1466-1475, 2007.

[166] K. A. Scheckel, S. C. Degner, and D. F. Romagnolo, "Rosmarinic acid antagonizes activator protein-1-dependent activation of cyclooxygenase- 2 expression in human cancer and nonmalignant cell lines," Journal of Nutrition, vol. 138, no. 11, pp. 20982105, 2008. 
[167] H. Wang, T. O. Khor, L. Shu et al., "Plants vs. cancer: a review on natural phytochemicals in preventing and treating cancers and their druggability," Anti-Cancer Agents in Medicinal Chemistry, vol. 12, no. 10, pp. 1281-1305, 2012.

[168] M. Iriti, R. Kubina, A. Cochis et al., "Rutin, a Quercetin Glycoside, Restores Chemosensitivity in Human Breast Cancer Cells," Phytotherapy Research, vol. 31, no. 10, pp. 1529-1538, 2017.

[169] H. E. Elsayed, H. Y. Ebrahim, M. M. Mohyeldin et al., "Rutin as A Novel c-Met Inhibitory Lead for The Control of Triple Negative Breast Malignancies," Nutrition and Cancer, vol. 69, no. 8, pp. 1256-1271, 2017.

[170] D. T. H. Verhoeven, R. A. Goldbohm, G. Van Poppel, H. Verhagen, and P. A. Van Den Brandt, "Epidemiological studies on Brassica vegetables and cancer risk," Cancer Epidemiology, Biomarkers \& Prevention, vol. 5, no. 9, pp. 733-748, 1996.

[171] J.-R. Weng, C.-H. Tsai, S. K. Kulp, and C.-S. Chen, "Indole-3carbinol as a chemopreventive and anti-cancer agent," Cancer Letters, vol. 262, no. 2, pp. 153-163, 2008.

[172] S. Fan, Q. Meng, T. Saha, F. H. Sarkar, and E. M. Rosen, "Low concentrations of diindolylmethane, a metabolite of indole-3carbinol, protect against oxidative stress in a BRCA1-dependent manner," Cancer Research, vol. 69, no. 15, pp. 6083-6091, 2009.

[173] W. Wang, M. Lv, Y. Wang, and J. Zhang, "Development of novel application of 3,3/-diindolylmethane: sensitizing multidrug resistance human breast cancer cells to $\gamma$-irradiation," Pharmaceutical Biology, vol. 54, no. 12, pp. 3164-3168, 2016.

[174] S. Lanza-Jacoby, K. Mcguire, and N. Ngoubilly, “3, 3' diindolylmethane, a Naturally Occurring Compound Found in Cruciferous Vegetables, Reduces Her-2/neu Signaling and Inhibits Growth of Her-2/neu-positive Breast Cancer Cells," The Journal of Nutrition, vol. 137, no. 1, article 290S, 2007.

[175] I. Chen, T. Hsieh, T. Thomas, and S. Safe, "Identification of estrogen-induced genes downregulated by AhR agonists in MCF-7 breast cancer cells using suppression subtractive hybridization," Gene, vol. 262, no. 1-2, pp. 207-214, 2001.

[176] M. Marques, L. Laflamme, I. Benassou, C. Cissokho, B. Guillemette, and L. Gaudreau, "Low levels of 3,3/-diindolylmethane activate estrogen receptor $\alpha$ and induce proliferation of breast cancer cells in the absence of estradiol," BMC Cancer, vol. 14, no. 1, article no. 524, 2014.

[177] S.-M. Heinonen, K. Wähälä, and H. Adlercreutz, "Identification of urinary metabolites of the red clover isoflavones formononetin and biochanin A in human subjects," Journal of Agricultural and Food Chemistry, vol. 52, no. 22, pp. 6802-6809, 2004.

[178] L. L. Atwell, Z. Zhang, M. Mori et al., "Sulforaphane bioavailability and chemopreventive activity in women scheduled for breast biopsy," Cancer Prevention Research, vol. 8, no. 12, pp. 1184-1191, 2015.

[179] J. M. Young, D. A. Brazeau, and M. E. Morris, "Effects of flavonoids genistein and biochanin $\mathrm{A}$ on gene expression and their metabolism in human mammary cells," Nutrition and Cancer, vol. 57, no. 1, pp. 48-58, 2007.

[180] Y. Wang, J. Yu, R. Cui, J. Lin, and X. Ding, "Curcumin in Treating Breast Cancer: A Review," Journal of Laboratory Automation, vol. 21, no. 6, pp. 723-731, 2016.

[181] T. Choudhuri, S. Pal, M. L. Agwarwal, T. Das, and G. Sa, "Curcumin induces apoptosis in human breast cancer cells through p53-dependent Bax induction," FEBS Letters, vol. 512, no. 1-3, pp. 334-340, 2002.
[182] H. Zong, F. Wang, Q.-X. Fan, and L.-X. Wang, "Curcumin inhibits metastatic progression of breast cancer cell through suppression of urokinase-type plasminogen activator by NFkappa B signaling pathways," Molecular Biology Reports, vol. 39, no. 4, pp. 4803-4808, 2012.

[183] B. E. Bachmeier, I. V. Mohrenz, V. Mirisola et al., "Curcumin downregulates the inflammatory cytokines CXCL1 and -2 in breast cancer cells via NF $\kappa$ B," Carcinogenesis, vol. 29, no. 4, pp. 779-789, 2008.

[184] M.-T. Lin, C.-C. Chang, S.-T. Chen et al., "Cyr61 expression confers resistance to apoptosis in breast cancer MCF-7 cells by a mechanism of NF- $\kappa \mathrm{B}$-dependent XIAP up-regulation," The Journal of Biological Chemistry, vol. 279, no. 23, pp. 2401524023, 2004.

[185] C. Lindvall, W. Bu, B. O. Williams, and Y. Li, "Wnt signaling, stem cells, and the cellular origin of breast cancer," Stem Cell Reviews and Reports, vol. 3, no. 2, pp. 157-168, 2007.

[186] S. Liu, G. Dontu, and M. S. Wicha, "Mammary stem cells, selfrenewal pathways, and carcinogenesis," Breast Cancer Research, vol. 7, no. 3, pp. 86-95, 2005.

[187] M. Labbozzetta, M. Notarbartolo, P. Poma et al., "Curcumin as a possible lead compound against hormone-independent, multidrug-resistant breast cancer," Annals of the New York Academy of Sciences, vol. 1155, pp. 278-283, 2009.

[188] P. Anand, A. B. Kunnumakkara, R. A. Newman, and B. B. Aggarwal, "Bioavailability of curcumin: problems and promises," Molecular Pharmaceutics, vol. 4, no. 6, pp. 807-818, 2007.

[189] Q. Guo, B. Zhao, M. Li, S. Shen, and X. Wenjuan, "Studies on protective mechanisms of four components of green tea polyphenols against lipid peroxidation in synaptosomes," Biochimica et Biophysica Acta, vol. 1304, no. 3, pp. 210-222, 1996.

[190] Y. Li, Y.-Y. Yuan, S. M. Meeran, and T. O. Tollefsbol, "Synergistic epigenetic reactivation of estrogen receptor- $\alpha$ (ER $\alpha)$ by combined green tea polyphenol and histone deacetylase inhibitor in ER $\alpha$-negative breast cancer cells," Molecular Cancer, vol. 9, article no. 274, 2010.

[191] M. G. Goodin, K. C. Fertuck, T. R. Zacharewski, and R. J. Rosengren, "Estrogen receptor-mediated actions of polyphenolic catechins in vivo and in vitro," Toxicological Sciences, vol. 69, no. 2, pp. 354-361, 2002.

[192] P. Wang, S. M. Henning, and D. Heber, "Limitations of MTT and MTS-based assays for measurement of antiproliferative activity of green tea polyphenols," PLoS ONE, vol. 5, no. 4, Article ID e10202, 2010.

[193] K. M. Baker and A. C. Bauer, "Green Tea Catechin, EGCG, Suppresses PCB 102-Induced Proliferation in Estrogen-Sensitive Breast Cancer Cells," International Journal of Breast Cancer, vol. 2015, Article ID 163591, 2015.

[194] M. R. Sartippour, R. Pietras, D. C. Marquez-Garban et al., "The combination of green tea and tamoxifen is effective against breast cancer," Carcinogenesis, vol. 27, no. 12, pp. 2424-2433, 2006.

[195] M. Alcaraz, D. Armero, Y. Martínez-Beneyto et al., "Chemical genoprotection: Reducing biological damage to as low as reasonably achievable levels," Dentomaxillofacial Radiology, vol. 40, no. 5, pp. 310-314, 2011.

[196] U. Ullmann, J. Haller, J. P. Decourt et al., "A single ascending dose study of epigallocatechin gallate in healthy volunteers," Journal of International Medical Research, vol. 31, no. 2, pp. 88$101,2003$.

[197] F. H. Sarkar and Y. Li, "Soy Isoflavones and Cancer Prevention," Cancer Investigation, vol. 21, no. 5, pp. 744-757, 2003. 
[198] E. Messing, J. R. Gee, D. R. Saltzstein et al., "A phase 2 cancer chemoprevention biomarker trial of isoflavone G-2535 (genistein) in presurgical bladder cancer patients," Cancer Prevention Research, vol. 5, no. 4, pp. 621-630, 2012.

[199] O. Kucuk, "Soy foods, isoflavones, and breast cancer," Cancer, vol. 123, no. 11, pp. 1901-1903, 2017.

[200] K. B. Bouker and L. Hilakivi-Clarke, "Genistein: Does it prevent or promote breast cancer?" Environmental Health Perspectives, vol. 108, no. 8, pp. 701-708, 2000.

[201] F. F. Zhang, D. E. Haslam, M. B. Terry et al., "Dietary isoflavone intake and all-cause mortality in breast cancer survivors: The Breast Cancer Family Registry," Cancer, vol. 123, no. 11, pp. 2070-2079, 2017.

[202] W.-F. Chen, M.-H. Huang, C.-H. Tzang, M. Yang, and M.-S. Wong, "Inhibitory actions of genistein in human breast cancer (MCF-7) cells," Biochimica et Biophysica Acta (BBA) - Molecular Basis of Disease, vol. 1638, no. 2, pp. 187-196, 2003.

[203] I. N. Sergeev, "Genistein induces Ca 2+-mediated, calpain/ caspase-12-dependent apoptosis in breast cancer cells," Biochemical and Biophysical Research Communications, vol. 321, no. 2, pp. 462-467, 2004.

[204] Y. Li, S. M. Meeran, S. N. Patel, H. Chen, T. M. Hardy, and T. O. Tollefsbol, "Epigenetic reactivation of estrogen receptor- $\alpha$ $(\mathrm{ER} \alpha)$ by genistein enhances hormonal therapy sensitivity in ER $\alpha$-negative breast cancer," Molecular Cancer, vol. 12, no. 1, article no. 9, 2013.

[205] C. Vissac-Sabatier, Y.-J. Bignon, and D. J. Bernard-Gallon, "Effects of the phytoestrogens genistein and daidzein on BRCA2 tumor suppressor gene expression in breast cell lines," Nutrition and Cancer, vol. 45, no. 2, pp. 247-255, 2003.

[206] Z. Yang, K. Kulkarni, W. Zhu, and M. Hu, "Bioavailability and pharmacokinetics of genistein: mechanistic studies on its ADME," Anti-Cancer Agents in Medicinal Chemistry, vol. 12, no. 10, pp. 1264-1280, 2012.

[207] S. H. Kwon, M. J. Kang, J. S. Huh et al., "Comparison of oral bioavailability of genistein and genistin in rats," International Journal of Pharmaceutics, vol. 337, no. 1-2, pp. 148-154, 2007.

[208] D. Lee, M. J. Kim, E. Song et al., "Nutrikinetic study of genistein metabolites in ovariectomized mice," PLoS ONE, vol. 12, no. 10, article e0186320, 2017.

[209] Y. Lu, D. Lin, W. Li, and X. Yang, "Non-digestible stachyose promotes bioavailability of genistein through inhibiting intestinal degradation and first-pass metabolism of genistein in mice," Food \& Nutrition Research, vol. 61, no. 1, article 1369343, 2017.

[210] Y. Lu, W. Li, and X. Yang, "Soybean soluble polysaccharide enhances absorption of soybean genistein in mice," Food Research International, vol. 103, pp. 273-279, 2018.

[211] T. R. Holzer, W. R. McMaster, and J. D. Forney, "Expression profiling by whole-genome interspecies microarray hybridization reveals differential gene expression in procyclic promastigotes, lesion-derived amastigotes, and axenic amastigotes in Leishmania mexicana," Molecular and Biochemical Parasitology, vol. 146, no. 2, pp. 198-218, 2006.

[212] N. Chalabi, L. Delort, L. Le Corre, S. Satih, Y. J. Bignon, and D. Bernard-Gallon, "Gene signature of breast cancer cell lines treated with lycopene," Pharmacogenomics, vol. 7, no. 5, pp. 663$672,2006$.

[213] K. S. Bishop and L. R. Ferguson, "The interaction between epigenetics, nutrition and the development of cancer," Nutrients, vol. 7, no. 2, pp. 922-947, 2015.
[214] X. Zhang, D. Spiegelman, L. Baglietto et al., "Carotenoid intakes and risk of breast cancer defined by estrogen receptor and progesterone receptor status: a pooled analysis of 18 prospective cohort studies," American Journal of Clinical Nutrition, vol. 95, no. 3, pp. 713-725, 2012.

[215] A. H. Eliassen, S. J. Hendrickson, L. A. Brinton et al., "Circulating carotenoids and risk of breast cancer: pooled analysis of eight prospective studies," Journal of the National Cancer Institute, vol. 104, no. 24, pp. 1905-1916, 2012.

[216] A. V. Rao and H. Shen, "Effect of low dose lycopene intake on lycopene bioavailability and oxidative stress," Nutrition Research, vol. 22, no. 10, pp. 1125-1131, 2002.

[217] A. Basu and V. Imrhan, "Tomatoes versus lycopene in oxidative stress and carcinogenesis: conclusions from clinical trials," European Journal of Clinical Nutrition, vol. 61, no. 3, pp. 295303, 2007.

[218] D. Raju, Junaid, I. Nazrul et al., "Molecular Insight and Binding Pattern Analysis of Shikonin as a Potential VEGFR-2 Inhibitor," Current Enzyme Inhibition, vol. 13, pp. 1-10, 2017.

[219] W. Han, L. Li, S. Qiu et al., "Shikonin circumvents cancer drug resistance by induction of a necroptotic death," Molecular Cancer Therapeutics, vol. 6, no. 5, pp. 1641-1649, 2007.

[220] S. Y. Jang, J. K. Lee, E. H. Jang, S. Y. Jeong, and J.-H. Kim, "Shikonin blocks migration and invasion of human breast cancer cells through inhibition of matrix metalloproteinase-9 activation," Oncology Reports, vol. 31, no. 6, pp. 2827-2833, 2014.

[221] W. Wang, M. Dai, C. Zhu et al., "Synthesis and biological activity of novel shikonin analogues," Bioorganic \& Medicinal Chemistry Letters, vol. 19, no. 3, pp. 735-737, 2009.

[222] L. Su, L. Liu, Y. Wang, G. Yan, and Y. Zhang, "Long-term systemic toxicity of shikonin derivatives in Wistar rats," Pharmaceutical Biology, vol. 52, no. 4, pp. 486-490, 2014.

[223] A. N. Assimopoulou and V. P. Papageorgiou, "Encapsulation of isohexenylnaphthazarins in cyclodextrins," Biomedical Chromatography, vol. 18, no. 4, pp. 240-247, 2004.

[224] K. L. Cheung and A.-N. Kong, "Molecular targets of dietary phenethyl isothiocyanate and sulforaphane for cancer chemoprevention," The AAPS Journal, vol. 12, no. 1, pp. 87-97, 2010.

[225] S. M. Meeran, S. N. Patel, and T. O. Tollefsbol, "Sulforaphane causes epigenetic repression of hTERT expression in human breast cancer cell lines," PLoS ONE, vol. 5, no. 7, Article ID e11457, 2010.

[226] Q. Li, G. Eades, Y. Yao, Y. Zhang, and Q. Zhou, "Characterization of a stem-like subpopulation in basal-like ductal carcinoma in situ (DCIS) lesions," The Journal of Biological Chemistry, vol. 289, no. 3, pp. 1303-1312, 2014.

[227] P. R. Dandawate, D. Subramaniam, R. A. Jensen, and S. Anant, "Targeting cancer stem cells and signaling pathways by phytochemicals: Novel approach for breast cancer therapy," Seminars in Cancer Biology, vol. 40, pp. 192-208, 2016.

[228] N. Hanlon, N. Coldham, A. Gielbert et al., "Absolute bioavailability and dose-dependent pharmacokinetic behaviour of dietary doses of the chemopreventive isothiocyanate sulforaphane in rat," British Journal of Nutrition, vol. 99, no. 3, pp. 559-564, 2008.

[229] Y. Li and T. Zhang, "Targeting cancer stem cells with sulforaphane, a dietary component from broccoli and broccoli sprouts," Future Oncology, vol. 9, no. 8, pp. 1097-1103, 2013.

[230] M. Athar, J. H. Back, L. Kopelovich, D. R. Bickers, and A. L. Kim, "Multiple molecular targets of resveratrol: Anti-carcinogenic mechanisms," Archives of Biochemistry and Biophysics, vol. 486, no. 2, pp. 95-102, 2009. 
[231] J. F. Savouret and M. Quesne, "Resveratrol and cancer: a review," Biomedicine \& Pharmacotherapy, vol. 56, no. 2, pp. 84-87, 2002.

[232] S. Jenkins, A. M. Betancourt, J. Wang, and C. A. Lamartiniere, "Endocrine-active chemicals in mammary cancer causation and prevention," The Journal of Steroid Biochemistry and Molecular Biology, vol. 129, no. 3-5, pp. 191-200, 2012.

[233] M. Park, K. Hwang, and K. Choi, "Diverse animal models to examine potential role(s) and mechanism of endocrine disrupting chemicals on the tumor progression and prevention: Do they have tumorigenic or anti-tumorigenic property?" Laboratory Animal Research, vol. 27, no. 4, pp. 265-273, 2011.

[234] K. P. L. Bhat, D. Lantvit, K. Christov, R. G. Mehta, R. C. Moon, and J. M. Pezzuto, "Estrogenic and antiestrogenic properties of resveratrol in mammary tumor models," Cancer Research, vol. 61, no. 20, pp. 7456-7463, 2001.

[235] E. Pozo-Guisado, J. M. Merino, S. Mulero-Navarro et al., "Resveratrol-induced apoptosis in MCF-7 human breast cancer cells involves a caspase-independent mechanism with downregulation of Bcl-2 and NF- $\kappa \mathrm{B}$," International Journal of Cancer, vol. 115, no. 1, pp. 74-84, 2005.

[236] A. Kotha, M. Sekharam, L. Cilenti et al., "Resveratrol inhibits Src and Stat 3 signaling and induces the apoptosis of malignant cells containing activated Stat 3 protein," Molecular Cancer Therapeutics, vol. 5, no. 3, pp. 621-629, 2006.

[237] S. Fulda and K.-M. Debatin, "Sensitization for tumor necrosis factor-related apoptosis-inducing ligand-induced apoptosis by the chemopreventive agent resveratrol," Cancer Research, vol. 64, no. 1, pp. 337-346, 2004.

[238] K. de Vries, M. Strydom, and V. Steenkamp, "Bioavailability of resveratrol: Possibilities for enhancement," Journal of Herbal Medicine, 2017.

[239] A. Y. Berman, R. A. Motechin, M. Y. Wiesenfeld, and M. K. Holz, "The therapeutic potential of resveratrol: a review of clinical trials," NPJ Precision Oncology, vol. 1, no. 1, article 35, 2017.

[240] C. Nguyen, J.-F. Savouret, M. Widerak, M.-T. Corvol, and F. Rannou, "Resveratrol, potential therapeutic interest in joint disorders: A critical narrative review," Nutrients, vol. 9, no. 1, article no. 45, 2017.

[241] C.-W. Chang, C.-Y. Wong, Y.-T. Wu, and M.-C. Hsu, "Development of a Solid Dispersion System for Improving the Oral Bioavailability of Resveratrol in Rats," European Journal of Drug Metabolism and Pharmacokinetics, vol. 42, no. 2, pp. 239-249, 2017.

[242] M. Karimi, H. Babaahmadi-Rezaei, G. Mohammadzadeh, and M.-A. Ghaffari, "Effect of silibinin on maspin and ER $\alpha$ gene expression in MCF-7 human breast cancer cell line," Iranian Journal of Pathology, vol. 12, no. 2, pp. 135-143, 2017.

[243] Z. Huang, G. Chen, and P. Shi, "Emodin-induced apoptosis in human breast cancer BCap-37 cells through the mitochondrial signaling pathway," Archives of Pharmacal Research, vol. 31, no. 6, pp. 742-748, 2008.

[244] P.-H. Huang, C.-Y. Huang, M.-C. Chen et al., "Emodin and Aloe-Emodin suppress breast cancer cell proliferation through ER $\alpha$ inhibition," Evidence-Based Complementary and Alternative Medicine, vol. 2013, Article ID 376123, 2013.

[245] J.-P. Xue, G. Wang, Z.-B. Zhao, Q. Wang, and Y. Shi, "Synergistic cytotoxic effect of genistein and doxorubicin on drug-resistant human breast cancer MCF-7/Adr cells," Oncology Reports, vol. 32, no. 4, pp. 1647-1653, 2014.

[246] C. Charalambous, C. A. Pitta, and A. I. Constantinou, "Equol enhances tamoxifen's anti-tumor activity by induction of caspase-mediated apoptosis in MCF-7 breast cancer cells," BMC Cancer, vol. 13, article no. 238, 2013.

[247] K. P. McGuire, N. Ngoubilly, M. Neavyn, and S. Lanza-Jacoby, "3,3I-Diindolylmethane and Paclitaxel Act Synergistically to Promote Apoptosis in HER2/Neu Human Breast Cancer Cells," Journal of Surgical Research, vol. 132, no. 2, pp. 208-213, 2006.

[248] M. González-Vallinas, S. Molina, G. Vicente et al., "Modulation of estrogen and epidermal growth factor receptors by rosemary extract in breast cancer cells," Electrophoresis, vol. 35, no. 11, pp. 1719-1727, 2014.

[249] C. Holohan, S. van Schaeybroeck, D. B. Longley, and P. G. Johnston, "Cancer drug resistance: an evolving paradigm," Nature Reviews Cancer, vol. 13, no. 10, pp. 714-726, 2013.

[250] M. D. Kars, Ö. D. Işeri, U. Gündüz, A. U. Ural, F. Arpaci, and J. Molnár, "Development of rational in vitro models for drug resistance in breast cancer and modulation of MDR by selected compounds," Anticancer Reseach, vol. 26, no. 6, pp. 4559-4568, 2006.

[251] H.-B. Xu, L. Li, J. Fu, X.-P. Mao, and L.-Z. Xu, "Reversion of multidrug resistance in a chemoresistant human breast cancer cell line by $\beta$-elemene," Pharmacology, vol. 89, no. 5-6, pp. 303312, 2012.

[252] B. J. Cridge, L. Larsen, and R. J. Rosengren, "Curcumin and its derivatives in breast cancer: current developments and potential for the treatment of drug-resistant cancers," Oncology Discovery, vol. 1, article 6, 2013.

[253] A. Shindikar, A. Singh, M. Nobre, and S. Kirolikar, "Curcumin and Resveratrol as Promising Natural Remedies with Nanomedicine Approach for the Effective Treatment of Triple Negative Breast Cancer," Journal of Oncology, vol. 2016, Article ID 9750785, 2016.

[254] C. Braicu, C. D. Gherman, A. Irimie, and I. Berindan-Neagoe, "Epigallocatechin-3-gallate (EGCG) inhibits cell proliferation and migratory behaviour of triple negative breast cancer cells," Journal of Nanoscience and Nanotechnology, vol. 13, no. 1, pp. 632-637, 2013.

[255] Y. Al Dhaheri, S. Attoub, G. Ramadan et al., "Carnosol induces ROS-mediated beclinl-independent autophagy and apoptosis in triple negative breast cancer," PLoS ONE, vol. 9, no. 10, Article ID e109630, 2014. 


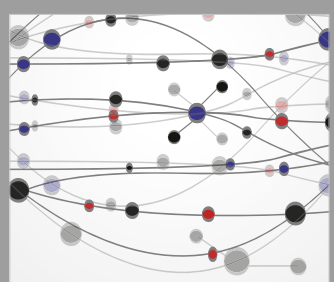

The Scientific World Journal
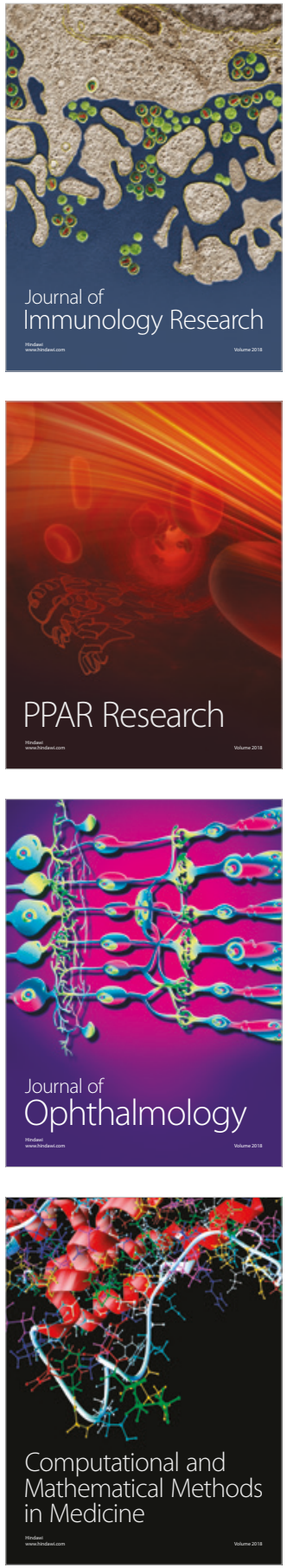

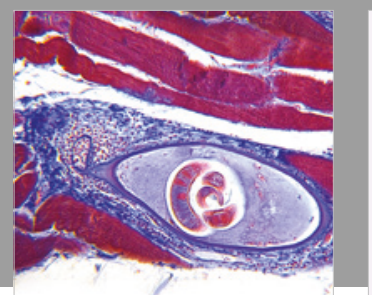

Gastroenterology Research and Practice

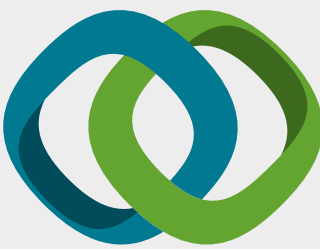

\section{Hindawi}

Submit your manuscripts at

www.hindawi.com
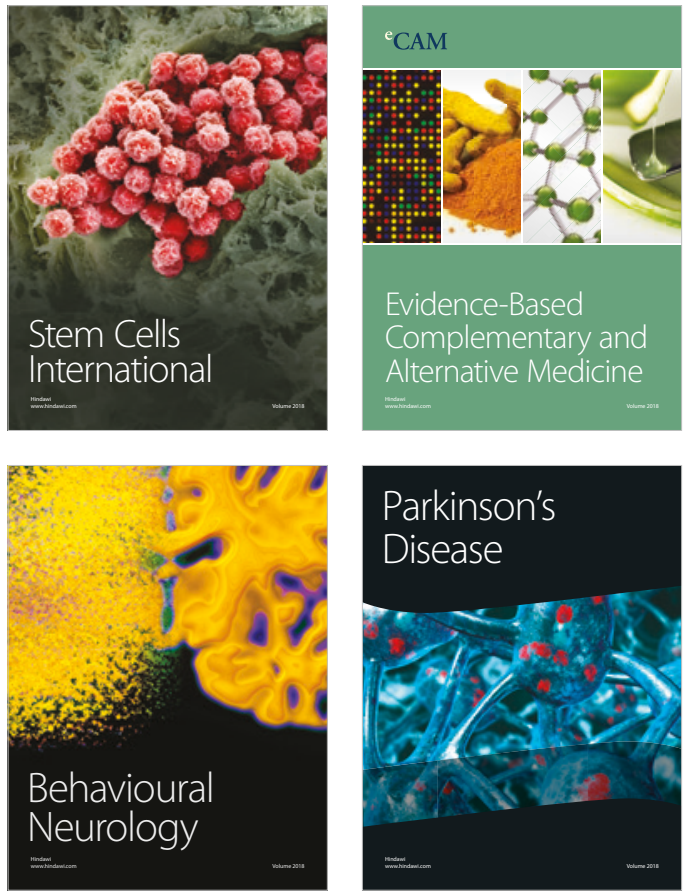

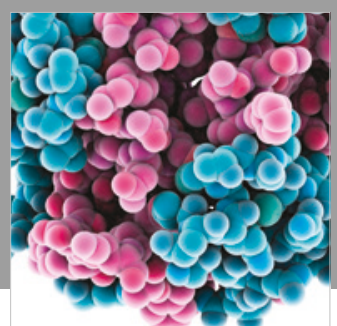

ournal of

Diabetes Research

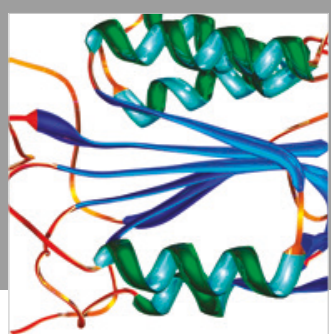

Disease Markers
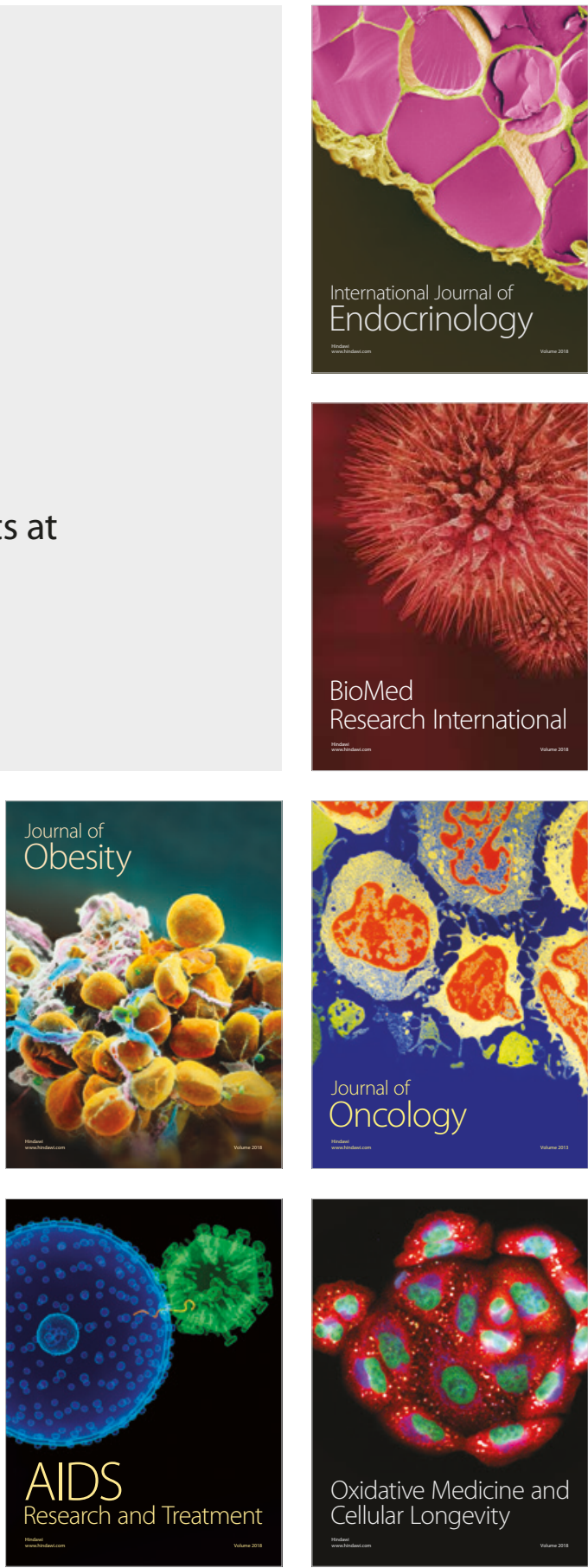